\title{
La incidencia de la Corte Suprema de Justicia en la formulación de políticas públicas: una exploración empírica del caso argentino
}

\author{
Álvaro Herrero
}

\section{Resumen}

Este artículo indaga acerca del rol de la Corte Suprema de Justicia de la Nación en el proceso de formulación de políticas públicas en Argentina. Tomando como estudio de caso las sentencias en materia previsional dictadas en el periodo 2005-2007 se analizan las distintas formas en que el máximo tribunal influyó en el diseño e implementación de la política pública previsional argentina en los últimos años. El principal hallazgo de esta investigación consiste en la comprobación empírica de un mayor protagonismo de la Corte Suprema en discusiones de política pública. A través de sus sentencias ella ha tenido un impacto decisivo en la revisión de los lineamientos centrales de la política previsional formulada durante la década de 1990 y en la construcción de un marco jurídico para la protección efectiva de los derechos de la clase pasiva.

Palabras Clave: Corte Suprema de Justicia, Políticas Públicas, Derecho Previsional, Activismo Judicial, Argentina.

\begin{abstract}
This article focuses on the role of the Supreme Court in the policy-making process in Argentina. Based on court rulings in pension cases rendered between 2005 and 2007, it analyzes the different ways in which the court influenced the design and implementation of pensions policy. Its main findings empirically confirm the Supreme Court's growing role in public policy discussions. The tribunal has had a decisive impact both in the revision of the core guidelines of the pension policies designed in the 1990s, and in the construction of a new legal framework for ensuring the effective protection of pension rights.
\end{abstract}

KEYWORDS: Supreme Court of Justice, policy-making process, pension policies, judicial activism, Argentina. 
$\mathrm{E}$ ste trabajo analiza una serie de sentencias de la Corte Suprema de Justicia de la Nación de Argentina dictadas a partir de 2005 relacionadas con casos referidos a las jubilaciones de los trabajadores retirados (conocidos también como casos 'previsionales'). El objetivo es describir la notoria influencia del accionar de la Corte - a través de dichas sentencias- en el diseño de la política pública previsional argentina. El rol del Poder Judicial, y más precisamente de la Corte Suprema, en los procesos que conducen a la formulación de políticas públicas ${ }^{1}$ ha sido objeto de creciente atención por parte de la academia. Sin embargo, no se ha consolidado un cuerpo de literatura que documente de manera precisa las distintas formas en que las cortes intervienen en dichos procesos y los resultados que dichas intervenciones generan.

El tema previsional ha estado en el centro de la agenda política argentina durante más de dos décadas. Su importancia radica en su doble impacto. Por un lado, la política previsional se relaciona con uno de los sectores más vulnerables de la sociedad: la clase pasiva. De su correcta aplicación depende el bienestar de quienes trabajaron durante décadas, realizaron aportes al sistema de seguridad social, y su supervivencia depende actualmente de la financiación del Estado. Por otro lado, el sistema previsional representa en términos de recursos financieros una porción elevada dentro del presupuesto nacional, por lo tanto, su 'salud' y estabilidad depende en gran medida del desempeño macroeconómico de los países durante décadas. A partir de los años 1970 Argentina, por ejemplo, ha sufrido recurrentes y agudas crisis económicas que afectaron negativamente los niveles de empleo y actividad industrial, al tiempo que generaron situaciones de déficit fiscal que comúnmente eran resueltas recurriendo -entre otros- a los recursos genuinos del sistema previsional.

Desde el regreso a la democracia en 1983 los distintos gobiernos se vieron con frecuencia impedidos de aumentar las jubilaciones y pensiones para adecuarlas a la evolución de los salarios debido a los mencionados problemas fiscales. Ante el deterioro del poder adquisitivo de sus haberes y la inacción estatal, miles de jubilados recurrieron a los tribunales para obtener el ajuste de sus jubilaciones. Dichos reclamos pusieron a la Corte Suprema ante un difícil escenario. La concesión de aumentos a los haberes previsionales implicaba no sólo imponer una pesada carga en una economía débil y muchas veces inestable, sino también poner en jaque la solidez y viabilidad financiera del sistema previsional. En cambio, el rechazo de los reclamos de los jubilados por parte de la Corte suponía la negación injustificada de los derechos previsionales de un extenso sector de la población que realizó por décadas sus aportes al sistema previsional pero que una vez retirado del mundo laboral recibe como contrapartida una magra jubilación.

$1 \quad$ Entiéndase por "políticas públicas" el conjunto de actividades de las instituciones de gobierno, actuando directamente o a través de agentes, y que van dirigidas a tener una influencia determinada sobre la vida de los ciudadanos (Peters, 1982). Son las acciones de gobierno que busca cómo dar respuesta a las diversas demandas de la sociedad (Alcántara, 1995). 
Con contadas excepciones, a partir de 1983, la Corte Suprema de Justicia de la Nación, en sus distintas conformaciones, evitó tanto obstaculizar como modificar la política previsional impulsada por los sucesivos gobiernos. Sin embargo, a partir de 2005, la Corte dictó una serie de sentencias que modificaron completamente las bases de la política previsional vigente y, además, forzaron tanto al Poder Ejecutivo como al Legislativo a tomar ciertas medidas para implementar cambios conducentes a la protección efectiva de los derechos previsionales de los ciudadanos.

Las reformas previsionales de la década de 1990 modificaron tanto los requisitos de acceso como las reglas para el cálculo de las jubilaciones². Como veremos más adelante, la nueva regulación condujo a situaciones de desprotección de los derechos previsionales de los ciudadanos, especialmente en lo referido a la actualización de las jubilaciones. Sin embargo, a partir de 2005 la Corte Suprema dictó una serie de fallos que revirtieron muchos de los retrocesos provocados por las reformas implementadas por el presidente Menem durante sus dos presidencias (1989-1999).

En segundo lugar se realiza una breve introducción sobre la relación entre justicia y política en América Latina. Posteriormente se repasan diversos enfoques sobre el rol del poder judicial en la formulación de políticas públicas. Luego se presenta una sucinta historia del sistema previsional argentino, para enseguida entrar de lleno en el análisis de las sentencias en materia previsional de la Corte Suprema entre 2005 y 2007. En una sexta parte se repasa el contexto económico y político en el cual fueron dictadas las sentencias de la Corte. Finalmente, presentamos las conclusiones.

\section{Justicia y Política en América Latina}

Por muchos años las ciencias sociales mostraron escaso interés en el Poder Judicial como objeto de investigación. Sin embargo, desde mediados de la década de 1980 la Ciencia Política y otras disciplinas afines comenzaron a concentrar su atención en diversos fenómenos asociados con jueces, cortes y sistemas de justicia. En años recientes, abogados, politólogos y economistas -entre otros- han

2 Al igual que en la mayoría de los países de la región, los dos ejes que definen las características de un sistema previsional son los requisitos de acceso y las reglas para el cálculo de los beneficios. Los requisitos de acceso se refieren a las condiciones requeridas para poder obtener la jubilación. Por lo general se exige haber alcanzado un mínimo de edad (en Argentina son 65 años para los hombres y 60 para las mujeres) y haber realizado aportes al sistema durante una determinada cantidad de años (en promedio, 30 años de servicio). Por su parte, las reglas para el cálculo del haber cumplen dos funciones. En primer lugar, permiten determinar qué salario se tomará como referencia para calcular el monto de la jubilación a pagar. En segundo lugar, establecen los mecanismos para realizar un ajuste o actualización periódica de la jubilación. Resumidamente, los requisitos de acceso permiten definir cuántas personas ingresarán al sistema, mientras que las reglas para el cálculo del haber sirven para determinar cuánto van a cobrar quienes ingresen al mismo. 
intentado explicar la naturaleza de la relación entre el Poder Judicial y el Poder Ejecutivo (Helmke, 2005; Iaryczower et al., 2000; Spiller et al., 2006); los patrones de interacción entre el Congreso y las cortes (Vanberg, 2001); y la forma en que la opinión pública influye sobre el comportamiento de los tribunales (Staton, 2002). Asimismo, diversas investigaciones se han orientado a las nuevas formas de intervención de las instituciones judiciales en el sistema político, como por ejemplo el fenómeno de la judicialización de la política (Guarnieri y Pederzoli, 2002; Skaar et al., 2004; Domingo, 2005; Sieder et al., 2005); el rol del Poder Judicial en las transiciones a la democracia (Ginsburg, 2003; Stotzky, 1993); y la influencia de los tribunales en la formulación de las políticas públicas (Tsebelis, 2002).

En lo que respecta a América Latina, este cambio se debió, en parte, a la ola de transiciones a la democracia que experimentaron muchos países de la región a partir de la década de 1980. Este proceso no fue un fenómeno autóctono sino parte de uno más amplio que afectó también a otras regiones del mundo (Huntington, 1996; Linz y Stepan, 1996). El florecimiento de procesos democráticos concitó la atención de los académicos, que comenzaron a interesarse por los distintos actores involucrados tanto en los periodos transicionales como en las etapas de consolidación de los nuevos sistemas de gobierno.

En dicho contexto, los especialistas en teoría democrática iniciaron una aproximación gradual a los poderes judiciales ya que éstos enfrentaban importantes desafíos directamente asociados con la consolidación de los nuevos regímenes, tales como juzgar las violaciones a los derechos humanos por parte de los gobiernos militares; contribuir a la vigencia del estado de derecho y la Constitución; investigar escándalos de corrupción; y someter al mandato de la ley a estructuras estatales acostumbradas a funcionar bajo esquemas autoritarios. Si bien en la década de 1980 ya existía un sólido cuerpo de literatura sobre autoritarismo y quiebres democráticos (Schmitter y O'Donnell, 1986; O'Donnell et al., 1986 y 1988; Diamond, Linz y Lipset; 1990), el inusitado protagonismo de las cortes en las nuevas transiciones democráticas dio lugar a una nueva etapa de investigación y producción literaria. Uno de los temas que generó mayor interés fue la capacidad de los poderes judiciales de la región de actuar en estos procesos de manera independiente y controlar a los otros poderes del Estado (Stotzky, 1993; Nino, 1997; Schedler et al., 1999; Przeworski et al., 1999; Teitel, 2002; Malamud Goti, 1996).

En el caso de Argentina, estos dos últimos temas fueron objeto de numerosos estudios, especialmente por las controversias generadas por la ampliación de la Corte Suprema de Justicia impulsada por el ex presidente Carlos Menem a comienzos de la década de 1990 y los posteriores cambios con motivo del Pacto de Olivos y la reforma constitucional de 1994 (Verbitsky, 1993). Un primer grupo de trabajo se concentró en la noción de independencia judicial y su aplicación en el caso argentino (Larkins, 1998a y 1998b; Finkel, 2004 y 2008; Helmke, 2003). Un segundo grupo, en cambio, analizó las relaciones entre la Corte Suprema y el Poder Ejecutivo bajo un enfoque 'positivo' en búsqueda de determinantes insti- 
tucionales de la conducta del poder judicial (Helmke, 2005; Iaryczower, 2000; Herrero, 2007; Kapisezwki, 2005).

\section{La Corte Suprema y políticas públicas}

Los enfoques institucionalistas nos han proporcionado información novedosa sobre el comportamiento de la Corte Suprema y especialmente valiosos indicios respecto a su influencia en el diseño de las políticas públicas. Por ejemplo, algunos autores sugieren que la mayor o menor cohesión del poder político influye de manera directa sobre la capacidad de la Corte Suprema de involucrarse en el proceso que conduce a la formación de políticas públicas. En esa línea, Ferejohn (2002) sostiene que cuando el mismo partido político controla los Poderes Ejecutivo y Legislativo, las posibilidades de que la Corte participe del citado proceso -por ejemplo, invalidando algún aspecto de una política regulada por ley- son muy bajas. En cambio, si distintos partidos controlan dichos Poderes, el tándem legislativo conformado por la legislatura y el Ejecutivo se vería incapacitado de funcionar, y por ende la capacidad real de la Corte de influir aumentaría.

Otros autores, por el contrario, han demostrado en el caso argentino que cuando el Poder Ejecutivo tiene control del Congreso (es decir, cuando el partido político del Presidente tiene mayoría en la legislatura), las probabilidades de que la Corte Suprema apoye -a través de acción o inacción-las políticas del Ejecutivo aumentan (Iaryczower, 2000; Herrero, 2007). También se ha comprobado que cuando el escenario electoral favorece la continuidad del presidente en ejercicio, la cantidad de fallos contra el Ejecutivo ha disminuido; mientras que los escenarios electorales adversos habrían motivado un aumento de dichas sentencias. Helmke (2005) caracteriza este comportamiento como una 'defección estratégica'. Esto se explicaría porque la capacidad del Poder Ejecutivo de 'castigar' a la Corte depende directamente del grado de control que aquél ejerza sobre el Congreso, ya que éste es quien puede, por medio del procedimiento de juicio político, sancionar al tribunal por su accionar. Frente a una Corte que declara inconstitucional la legislación que promueve las preferencias políticas del Presidente, el único factor disuasivo disponible por este último es promover la remoción de los jueces de la Corte Suprema. El famoso caso del enfrentamiento entre el presidente Francis Delano Roosevelt y la Corte Suprema de Estados Unidos es un buen (y reiterado) ejemplo de este escenario (Shaw, 2004).

Sin embargo, no existe mucha evidencia sobre la forma específica en que el accionar de la Corte Suprema de Justicia de la Nación influye en el diseño de políticas públicas en Argentina. En otros países, especialmente en Estados Unidos, existen valiosos antecedentes sobre el tema. Comenzando con el trabajo seminal de Dahl (1957) y pasando por la obra de Shapiro (1968; 1981), entre muchos otros (Jackson y Tate, 1992; Tsebelis, 2000), diversos investigadores han procurado entender la forma en que las instituciones judiciales intervienen en la 
formación de las políticas estatales en temas diversos, como por ejemplo la regulación de la economía, el diseño de políticas educativas (Rosenberg, 1991; 2004), y la reforma de los sistemas carcelarios (Feeley, 1998). Más allá de proposiciones normativas -la forma en que idealmente se concibió el rol del Poder Judicial en el sistema constitucional de cada país-, el objetivo central de este enfoque es entender cómo las instituciones judiciales operan en la práctica, procurando identificar de manera empírica patrones concretos de interacción entre el sistema de justicia y los actores responsables de la formulación de políticas estatales. En América Latina, por el contrario, el estado del análisis académico en esta materia se encuentra aún en una etapa temprana.

\section{Breve historia del sistema previsional argentino ${ }^{3}$}

El origen del sistema previsional argentino se remonta al año 1904 con la creación de un esquema de jubilaciones para empleados del sector público. Dicho sistema experimentó un crecimiento sostenido durante las primeras décadas del siglo XX, llegando a índices inusitados de cobertura de la fuerza laboral en la década de 1950 en función del surgimiento del movimiento obrero y su posicionamiento como actor protagónico en el escenario político. En los años '60 se introdujeron cambios importantes al sistema, como por ejemplo la obligación de que las jubilaciones fueran equivalentes al $82 \%$ del valor del salario de un trabajador activo del mismo sector (Ley 14.449). Asimismo, se estableció que el importe de las jubilaciones podría ser actualizado periódicamente por el Poder Ejecutivo de acuerdo a la variación del 'Índice de Costo de Vida', un indicador de la evolución de los precios de bienes y servicios.

La generosidad de los requisitos para acceder a los beneficios previsionales impuso gradualmente una pesada carga al sistema, poniendo en riesgo su sostenibilidad financiera. Para remediar la situación la Ley 18.037 (1968) unificó la mayoría de los fondos especiales de pensión (maestros, empleados públicos, trabajadores industriales) en tres grandes cajas previsionales: Empleados Públicos, Autónomos, e Industria. Asimismo, se fijaron edades mínimas para acceder a la jubilación (algo inexistente hasta entonces) en 60 años para los hombres y 55 para las mujeres, y se fijaron nuevos estándares mínimos para el cálculo de los haberes en una banda que oscilaba entre el 70\% y el 82\% de los sueldos de los trabajadores activos. Finalmente, se estableció que las jubilaciones debían ser actualizadas de acuerdo a la variación del Índice General de Remuneraciones, un indicador que reflejaba los cambios anuales en los salarios.

El sistema se mantuvo relativamente estable pese a la disparidad entre, por un lado, la extensión de los beneficios y, por otro, la laxitud de los requisitos de

3 Para un minucioso repaso de la historia del sistema previsional argentino, ver Rofman (2000) y Bertranou (2003). 
acceso y las reducidas contribuciones de los trabajadores activos. Sin embargo, la caída sostenida del PBI y de los salarios entre 1970 y 1990 afectó negativamente la estabilidad del sistema. Como explica Rofman (2002), durante gran parte de la década de 1980 el sistema tuvo un creciente déficit, financiado en parte por la postergación indebida de los ajustes a los beneficios según el costo de vida. Esta estrategia tuvo como resultado un proceso de movilización legal que se manifestó en la iniciación de juicios masivos contra el Estado, que eventualmente fueron ganados de manera sistemática por los jubilados. A comienzos de los años 90 se volvió evidente la necesidad de una reforma del sistema previsional.

En ese contexto, en 1993, luego de extensos debates, el Congreso aprobó un paquete de reformas impulsadas por el presidente Carlos Menem ${ }^{4}$. Los principales cambios consistieron en modificaciones notorias tanto en los parámetros básicos del sistema previsional (incrementos en la edad mínima y años de contribuciones requeridas para jubilarse, y nivel de las contribuciones), como en las características estructurales del mismo. Además del sistema estatal (conocido también como sistema de reparto) se creó uno de capitalización, donde los trabajadores podían acumular sus contribuciones en cuentas individuales administradas por empresas privadas denominadas Administradoras de Fondos de Jubilaciones y Pensiones (AFJP).

Posteriormente, en 1995, el presidente Menem impulsó un nuevo paquete de reformas que fue aprobado por el Congreso por medio de la llamada Ley de Solidaridad Previsional ${ }^{5}$. Los principales cambios consistieron en la eliminación de todos los mecanismos existentes para la actualización automática de las jubilaciones, y en la creación de un fuero judicial especializado para atender los juicios contra el sistema previsional. El impacto de dichas reformas fue notorio. Por un lado, se prohibieron los ajustes automáticos de las jubilaciones. El gobierno ya no podía por sí solo aumentar las jubilaciones sino que debía implementarse por una ley del Congreso de la Nación siempre y cuando hubiera fondos suficientes para hacerlo. Por otro lado, se hizo más complejo el reclamo por vía judicial de la protección de los derechos previsionales ${ }^{6}$. La creación de un fuero especializado tenía por objetivo asegurar un tratamiento homogéneo de los reclamos de los jubilados, pero el tiempo demostró que ello fue utilizado para demorar injustificadamente el reconocimiento efectivo de los derechos de la clase pasiva.

Asimismo, la Ley de Solidaridad Previsional introdujo un cambio importante en el ámbito judicial: la instauración de una instancia de apelación ordinaria en

\footnotetext{
Ley 24.241 .

Ley 24.463.

La reforma procesal en materia previsional se completó al año siguiente con la creación del Fuero Federal de la Seguridad Social (Ley 24.655 del 5/6/1996). A partir de su creación todos los nuevos reclamos relacionados con jubilaciones y pensiones debían iniciarse en los nuevos tribunales de la Seguridad Social. Por su parte, las apelaciones se dirimían en la ya existente Cámara Federal de Apelaciones de la Seguridad Social.
} 
materia previsional ante la Corte Suprema ${ }^{7}$. En la práctica, esto implicó que absolutamente todos los casos previsionales resueltos por las Cámaras de Apelaciones podían ser apelados ante el máximo tribunal. De esa forma, miles de casos comenzaron a llegar a la Corte, puesto que ya no era necesario que existiera una cuestión constitucional para acceder al tribunal sino que bastaba con una simple apelación. Los objetivos políticos de este cambio eran, por un lado, dilatar la resolución de los casos - mediante la creación de una tercera instancia ordinaria- y consecuentemente retrasar el pago de las sentencias contra el Estado; y por otro lado, asegurarse que todos los casos llegaran a la Corte Suprema para así garantizar un tratamiento homogéneo y favorable al gobierno. Vale recordar que tan sólo unos años antes el gobierno del presidente Menem había impulsado con éxito la ampliación de dicho tribunal, aumentando de cinco a nueve el número de sus miembros y nombrando una mayoría afín al Poder Ejecutivo

\subsection{LOS FALLOS DE LA CORTE SUPREMA EN MATERIA PREVISIONAL}

El apoyo de la Corte Suprema de los años 90 a la política previsional del gobierno del presidente Menem se hizo evidente en diversos casos. En esa época las preferencias del gobierno se relacionaban con una preocupación fiscal: el deseo del Poder Ejecutivo de evitar que las sentencias judiciales otorgaran aumentos por ajuste a los jubilados. Si bien Menem había logrado reducir la tasa de inflación -al punto de alcanzar una situación de deflación ${ }^{8}-$, los altos índices de desempleo ${ }^{9}$, la migración de los trabajadores al sistema de jubilación de capitalización individual, y la evasión impositiva, agudizó la crisis de sistema de jubilaciones estatal ${ }^{10}$. En 1996 alrededor del 60\% del déficit del sector público se relacionaba con las dificultades del sistema previsional ${ }^{11}$, lo que forzó al gobierno a canalizar 3.480 millones de dólares para poder hacer frente a los compromisos previsionales de ese año.

En dicho contexto, el Poder Ejecutivo deseaba evitar que la intervención judicial aumentara la presión sobre las finanzas del gobierno y pusiera en riesgo el compromiso asumido con el Fondo Monetario Internacional de mantener el déficit fiscal por debajo de los 6.000 millones de dólares. Además, las perspectivas económicas para 1997 eran desalentadoras. Los expertos pronosticaban que el gobierno no podría cumplir las metas fiscales ${ }^{12}$, lo cual incluía un paquete de rescate de 1.500 millones de dólares para el sistema previsional.

Artículo 19, Ley 24.463.

La Nación, 3/1/1997. 'La inflación más baja en 43 años'.

La Nación, 8/1/1997. 'Sería del 17,6\% la tasa de desempleo a nivel nacional'.

10 A esto debe agregársele los efectos negativos en la economía argentina a causa de la llamada 'crisis Tequila' en 1994.

11 La Nación, 12/01/1997. 'Encrucijada Previsional'.

12 El FMI reclamaba que en 1997 se mantuviera el déficit por debajo de 4.500 millones de dólares, pero los pronósticos locales más optimistas hablaban de un piso mínimo de entre 5.500 y 6.500 millones. Véase La Nación, 11/01/1997. Pronostican un Déficit Más Alto; La Nación, 10/01/1997. 'Prometen al FMI un severo ajuste'. 
Alineándose con las preferencias del Poder Ejecutivo, en el caso 'Chocobar'13, la Corte Suprema reconoció un reajuste del 13,78\% en las jubilaciones para el periodo comprendido entre el 1 de abril de 1991 y el 31 de marzo de 1994. El Tribunal entendió que con la entrada en vigencia de la Ley de Convertibilidad (23.928) quedaba derogado el sistema de movilidad de las jubilaciones impuesto por la ley 18.037, por lo cual rechazó el ajuste del 35\% reclamado por el demandante. Según La Nación, el Ministerio de Economía y la Secretaría de Seguridad Social celebraron la sentencia de la Corte Suprema, especialmente por su implicancia para casos análogos ${ }^{14}$. Este precedente se aplicó a unas 70.000 causas judiciales en trámite en el fuero de la seguridad social ${ }^{15}$.

Por el contrario, la oposición recibió con desagrado la decisión del Tribunal. El diputado Héctor Polino, por ejemplo, solicitó el juicio político para los cinco jueces que votaron en la mayoría ${ }^{16}$. Sin embargo, el férreo control del partido de gobierno sobre el Poder Legislativo impidió que se enjuiciara a los magistrados.

Posteriormente, en el caso 'Heit Rupp'17, la Corte volvió a apoyar la política previsional del gobierno. En dicha oportunidad el tribunal resolvió que no se podía reconocer movilidad alguna para las jubilaciones a partir del 1/4/1995 y hasta que el Congreso fijara anualmente dicha movilidad en la Ley de Presupuesto. De esa forma limitó la aplicación de la movilidad reconocida en 'Chocobar' hasta la sanción de la Ley de Solidaridad Previsional (24.463). De allí en adelante no se pudo aplicar ningún tipo de ajuste excepto por disposición del Congreso. Esta doctrina se mantuvo vigente desde 1999 hasta el dictado del fallo 'Badaro' en 2006.

\subsection{FALLOS DE LA CORTE SUPREMA ENTRE 2005 y 2007}

La renovación de la composición de la Corte Suprema iniciada en 2003 dio lugar a la revisión de la doctrina previsional sentada por la anterior conformación durante la década de 1990. Entre 2003 y 2005 seis de los nueve jueces dejaron el tribunal. El principal motivo de dicho cambio fue el pedido de juicio político impulsado por el presidente Néstor Kirchner contra cinco jueces nombrados por el presidente Menem, que históricamente habían sido cuestionados por su excesiva proclividad a apoyar desde el tribunal las políticas del Poder Ejecutivo. Si bien Menem y Kirchner pertenecían al mismo partido político (Partido Justicialista), el gobierno del primero tuvo numerosas acusaciones por graves hechos de corrupción y reproches por reformas que debilitaron el sistema republicano de gobierno, como por ejemplo la ampliación de la Corte Suprema (Verbitsky 1993).

13 Corte Suprema de Justicia de la Nación (CSJN), 'Chocobar, Sixto c/Caja Nacional de Previsión para el Personal del Estado y Servicios Públicos'. Sentencia del 27 de diciembre de 1996.

4 La Nación, 04/01/1997. 'Los Jubilados ya no tienen el 82\%'.

15 Clarín, 10/4/2005; La Nación, 10/4/2005.

16 La Nación, 30/12/1996. 'Piden juicio político a miembros de la Corte'.

17 CSJN, 'Heit Rupp, Clementina c/ ANSES s/reajustes por movilidad', sentencia de 16/08/1999. 
La incidencia de la Corte Suprema de Justicia en la formulación de políticas públicas...

CUADRO 1

Respuesta de la Corte Suprema en el caso Chocobar

\begin{tabular}{|c|c|c|}
\hline DEMANDA & $\begin{array}{c}\text { PREFERENCIAS DEL PODER } \\
\text { EJECUTIVO }\end{array}$ & $\begin{array}{c}\text { INTERVENCIÓN DE LA CORTE } \\
\text { SUPREMA }\end{array}$ \\
\hline $\begin{array}{l}\text { Reclamo de actualización por } \\
\text { movilidad entre } 1991 \text { y } 1995 \\
\text { ('Chocobar') }\end{array}$ & $\begin{array}{l}\text {-Minimizar el ajuste de las } \\
\text { jubilaciones por movilidad. } \\
\text {-Reducir el gasto fiscal. } \\
\text {-Reducir el impacto fiscal de } \\
\text { las sentencias previsionales. }\end{array}$ & $\begin{array}{l}\text {-Rechazó el ajuste de 35\% } \\
\text { pedido por el Sr. Chocobar. } \\
\text {-Rechazó la validez de los } \\
\text { mecanismos automáticos de } \\
\text { movilidad. } \\
\text {-Reconoció un ajuste de 13\% } \\
\text { para las jubilaciones entre } 1991 \\
\text { y } 1994 .\end{array}$ \\
\hline
\end{tabular}

Fuente: Elaboración propia

Una de las primeras medidas del presidente Kirchner fue solicitar el juicio político a los jueces nombrados por Menem. Los magistrados Eduardo Moliné O'Connor y Antonio Boggiano fueron removidos mediante el citado mecanismo. Por su parte, Julio Nazareno, Adolfo Vázquez y Guillermo López renunciaron para evitar ser enjuiciados. Poco tiempo después, Augusto Belluscio renunció por haber llegado al límite de 75 años de edad que establece la Constitución ${ }^{18}$.

Dadas las vacantes por la salida de los jueces mencionados, el presidente Kirchner postuló a Raúl Zaffaroni, Elena Highton de Nolasco, Carmen Argibay y Ricardo Lorenzetti para integrar el máximo tribunal. Las otras dos vacantes no fueron completadas ya que el Congreso dispuso la reducción de la Corte Suprema de nueve a cinco integrantes. Como al momento de sancionarse la ley el tribunal contaba con siete miembros, ella dispuso que las próximas vacantes no fuesen cubiertas para así llegar al número de cinco jueces. De todos modos, la designación de cuatro nuevos magistrados sobre un total de siete fue un cambio notorio ya que se modificó sustancialmente su composición.

En su renovada conformación, el eje de las nuevas decisiones de la Corte Suprema en materia previsional se caracterizó por una reexaminación de la validez de los mecanismos de movilidad, de la vigencia de los regímenes especiales de jubilación, y de la constitucionalidad de la apelación ordinaria en materia previsional ante la Corte Suprema. A continuación se analizan cuatro fallos clave del máximo tribunal dictados entre 2005 y 2007 que tuvieron un impacto decisivo en la política previsional vigente en la Argentina.

18 Augusto Belluscio había sido nombrado juez de la Corte Suprema por el presidente Alfonsín en 1983. El artículo 99 inciso 4 de la Constitución Argentina establece que una vez que los jueces de la Corte Suprema lleguen a los 75 años de edad, podrán ser reconfirmados en el cargo mediante la prestación de un nuevo acuerdo por parte del Senado. Este proceso deberá repetirse cada cinco años. 


\subsection{APELACIÓN ORDINARIA EN MATERIA PREVISIONAL ANTE LA CORTE SUPREMA: 'ITZCOVICH'19}

La Ley de Solidaridad Previsional, sancionada en 1995, instauró una instancia de apelación ordinaria en casos previsionales ante la Corte Suprema de Justicia de la Nación ${ }^{20}$. Dicha norma estableció que la sentencia definitiva de la Cámara Federal de la Seguridad Social podía apelarse ante la Corte Suprema de Justicia de la Nación mediante recurso ordinario, cualquiera fuese el monto del juicio. Asimismo, dispuso que los fallos de la Corte Suprema de Justicia de la Nación fuesen de seguimiento obligatorio para los jueces inferiores en el tratamiento de causas análogas. Esto lo transformó en un tribunal de tercera instancia, desdibujando su rol de tribunal constitucional ${ }^{21}$. Debido al nuevo sistema, se produjo a su vez, un aumento en el volumen de trabajo. Además de los 2.000 recursos extraordinarios que la Corte solía resolver por año, se le sumaron otros 10.000

\section{CUADRO 2}

Evolución de casos previsionales ante la Corte Suprema por apelación ordinaria.

CASOS PREVISIONALES INGRESADOS

CORTE SUPREMA DE JUSTICIA DE LA NACIÓN (POR AÑO)

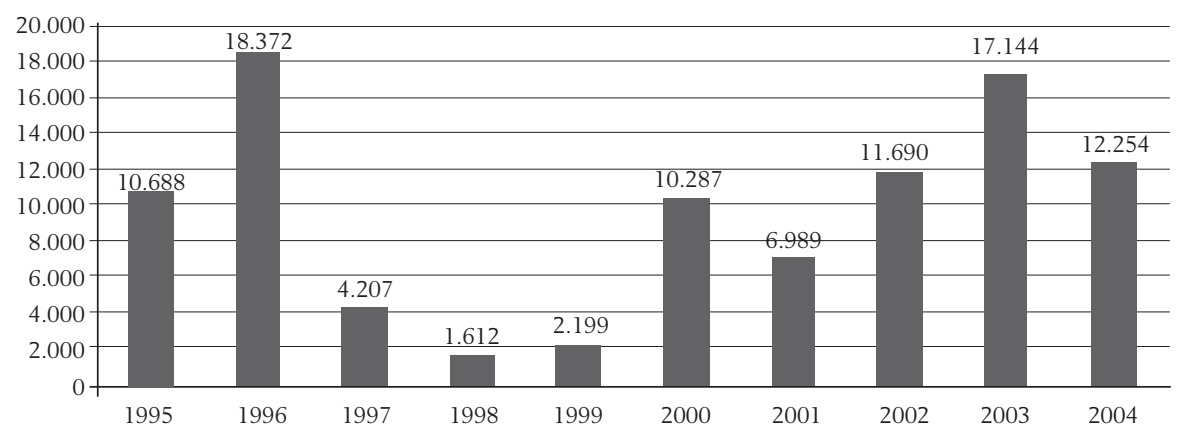

Fuente: Oficina de Estadísticas, Corte Suprema de Justicia de la Nación.

19 CSJN, 'Itzcovich, Mabel c/ ANSES s/ reajustes varios', sentencia del 29 de marzo de 2005.

Art. 19 de la ley 24.463

21 En el sistema de justicia argentino los casos llegan a la Corte Suprema de Justicia por dos vías. La primera es la competencia originaria, que es cuando actúa como tribunal de primera instancia. La Constitución le otorga a la Corte competencia para decidir en forma originaria -es decir, primera y exclusivamente- en las causas concernientes a embajadores, ministros y cónsules extranjeros, y en los que alguna provincia sea parte. La segunda es la competencia por apelación, que es cuando revisa sentencias provenientes de tribunales inferiores por vía del recurso extraordinario federal. Es en este tipo de casos donde la Corte cumple fundamentalmente su rol de último intérprete de la Constitución Nacional, ya que en ellos se interpreta el significado y alcance de la Constitución, leyes federales y tratados, como también los conflictos que puedan surgir entre la Constitución y las leyes nacionales o provinciales. La creación de una competencia por apelación ordinaria en casos previsionales permitió que llegaran a la Corte casos de escasa relevancia donde no estaban en juego discusiones constitucionales. 
recursos ordinarios. Según datos oficiales, entre 1995 y 2004 la Corte recibió 95.000 casos previsionales por la mencionada vía recursiva ${ }^{22}$. Como resultado, se incrementaron los tiempos de resolución y se produjeron sustantivas demoras en la decisión de los expedientes.

Uno de los objetivos declarados, al momento de la Ley de Solidaridad Previsional, era agilizar los tiempos de decisión de los casos y garantizar un correcto tratamiento de ese tipo de cuestiones sensibles para la protección de los derechos de la clase pasiva. Según los legisladores, la creación de un recurso de apelación ordinario contribuiría a moderar el altísimo índice de litigiosidad en materia de seguridad social y evitar el dispendio jurisdiccional. Asimismo, la Ley de Solidaridad Previsional tenía como objetivo enfrentar el déficit estructural del sistema previsional, cuya solvencia se veía en peligro, y restablecer la solidaridad de dicho régimen. En ese contexto, la instauración de una tercera instancia ante la Corte Suprema permitía asegurar que los miles de casos previsionales que llegaban al Tribunal fueran resueltos de manera uniforme ${ }^{23}$. Si bien individualmente los montos de los reclamos podían ser menores, su volumen agregado seguramente tendría un impacto significativo sobre las cuentas fiscales. De allí que el gobierno del presidente Menem pretendiera asegurar que el resultado de los reclamos judiciales fuera acorde a sus expectativas, lo que en la práctica significaba reducir al mínimo el peso económico de las sentencias previsionales de la Corte Suprema.

Sin embargo, dicho mecanismo repercutió negativamente sobre la protección de los derechos en juego en los casos previsionales, ya que la capacidad operativa del Tribunal se vio desbordada por la elevada cantidad de apelaciones ordinarias y, por ende, los tiempos de tramitación de dichos casos se alargaron de manera considerable. Lejos de alcanzar los propósitos esgrimidos por los legisladores al sancionar la ley, la instauración de una tercera instancia ordinaria resultó en mayores dilaciones. De esa forma, en lugar de proteger a los jubilados la Ley de Solidaridad Previsional terminó agravando su situación al privarlos de una vía judicial rápida para reclamar por una jubilación adecuada para llevar una vida digna.

En 2005 la Corte Suprema dictó sentencia en un caso donde se cuestionaba la constitucionalidad de la instancia de apelación ordinaria creada por la ley 24.463. La demanda sostenía que el recurso de apelación ordinario ante la Corte violaba garantías constitucionales y el derecho a un proceso sencillo y breve contemplado en diversas convenciones internacionales. Asimismo, indicó que la ley 24.463 instituyó un sistema de vallas para impedir que los jubilados tuvieran un

22 Fuente: Oficina de Estadísticas del Poder Judicial de la Nación. Disponible el 25/6/2008 en http://www. pjn.gov.ar/

23 Cabe recordar que unos pocos años antes, en 1991, el Congreso había ampliado la conformación de la Corte Suprema de Justicia, llevándola de cinco a nueve jueces. Dada la renuncia de uno de los magistrados del Tribunal en disconformidad por la ampliación, el presidente Menem tuvo la oportunidad de designar a cinco de los nueve integrantes, contando así con una mayoría propia que le aseguró un apoyo constante a sus políticas. 
acceso efectivo y rápido a la justicia, al imponerles la necesidad de aguardar los resultados de la apelación ordinaria ante la Corte después de haber agotado el procedimiento administrativo y debatido en dos instancias judiciales. Finalmente, sostuvo que la instauración de una tercera instancia, lejos de cumplir con los propósitos planteados por la ley, significó importantes demoras en los procesos previsionales, impidiendo que los reclamantes obtuvieran una respuesta en un tiempo razonable.

En su sentencia en el caso 'Itzcovich', la Corte declaró la inconstitucionalidad del artículo 19 de la ley 24.463. El fallo sostuvo que la competencia por apelación ordinaria creada por la Ley de Solidaridad Previsional se volvió indefendible ya que en la práctica no sirvió a los fines que fueron tomados en consideración al momento de su sanción. Luego de repasar los principales argumentos utilizados por el legislador (moderar el altísimo índice de litigiosidad, dar mayor previsibilidad al sistema, agilizar los tiempos de decisión de los casos y garantizar un correcto tratamiento de ese tipo de cuestiones sensibles para la protección de los derechos de la clase pasiva), la Corte concluyó que ninguno de ellos se había concretado en la práctica y, más aún, que el resultado había sido contrario a los propósitos de la ley. La sentencia destacó que el organismo previsional no hizo un uso apropiado del recurso en cuestión. En gran parte de los casos todo el tiempo y esfuerzos requeridos para la tramitación de las apelaciones ordinarias resultaron innecesarios y no hizo más que postergar injustificadamente el cobro del crédito de carácter alimentario que había sido reconocido en las instancias anteriores ${ }^{24}$.

La Corte señaló también que la apelación ordinaria tuvo un impacto negativo ya que comprometió el rol institucional del máximo tribunal. En tal sentido, sostuvo que luego de más de diez años de aplicación de la cuestionada norma, la evidencia empírica había demostrado que la vigencia del procedimiento establecido por el art. 19 de la Ley de Solidaridad Previsional tuvo como consecuencia una gran expansión en el ámbito de competencia de la Corte, con la consiguiente alteración de su rol natural como intérprete final de la Constitución Nacional.

Por último, el fallo remarcó que la apelación ordinaria causó graves perjuicios a los justiciables en una etapa de la vida en que la tutela estatal resulta imprescindible. El procedimiento previsional se vincula con personas que han concluido su vida laboral y, en la mayoría de los casos, dependen para su sustento de la efectiva percepción de las jubilaciones o pensiones que les corresponden por mandato constitucional. Sin embargo, los reclamantes se vieron afectados por las extensas demoras causadas por la apelación ordinaria, que en la práctica no hizo otra cosa que postergar injustificadamente el efectivo cobro de sus créditos.

A menos de un mes de emitida la sentencia, el Congreso dictó la ley 26.025 que derogó el artículo 19 de la ley de Solidaridad Previsional y con ello eliminó

24 La sentencia del caso Itzcovich, al igual que todas las dictadas por la Corte Suprema de Justicia de la Nación y citadas en este artículo, están disponibles en el sitio de Internet del tribunal. Para acceder a ellos se debe ingresar en la sección "Fallos Completos" en: http://www.csjn.gov.ar/jurisprudencia.html 
para el futuro la competencia ordinaria de la Corte para resolver ese tipo de casos. Si bien le tomó más de una década enmendar su error, la intervención del Congreso representó un respaldo al accionar del máximo tribunal al dictar el fa1lo 'Itzcovich' ${ }^{25}$. Según estimaciones del Senado, unos 30.000 juicios con fallo de la cámara previsional quedaron con sentencia firme a partir de la derogación de la apelación ordinaria ${ }^{26}$. De esa forma se eliminó una importante barrera judicial a los reclamos por ajustes previsionales evitando que los jubilados tuvieran que pasar por una tercera instancia para obtener una respuesta a sus reclamos.

Desde el punto de vista político, el gobierno del presidente Kirchner recibió con agrado la sentencia del caso Itzcovich ya que coincidía con su prioridad de mejorar la situación de los jubilados. Sin embargo, desde un punto de vista económico, los asesores de Kirchner se preocuparon por el impacto de la sentencia en el mediano y largo plazo. Si bien el gobierno ya había comprometido los fondos necesarios para pagar 19.000 sentencias durante 2005, la aplicación inmediata del fallo de la Corte implicaba que se ese año se deberían pagar unas 9.000 sentencias adicionales ${ }^{27}$, aumentando la presión sobre el frente fiscal.

\subsection{LA MOVILIDAD DE LAS JUBILACIONES ENTRE 1991 Y 1995: 'SÁNCHEZ’28}

En 2005 la Corte Suprema retomó los casos relacionados con la aplicación de ajustes por movilidad en el periodo comprendido entre 1991 y 1995. Debía resolverse qué mecanismo debía aplicarse para actualizar las jubilaciones en dicho periodo. En 1991 el Congreso sancionó la Ley de Convertibilidad que -entre otras cosas- prohibió efectuar ajustes por indexación de prestaciones en dinero. Posteriormente, en 1995 se sancionó la Ley de Solidaridad Previsional que -como ya se explicó- eliminó expresamente todo mecanismo automático para fijar la movilidad de las jubilaciones y estableció que la misma se determinaría anualmente mediante la Ley de Presupuesto conforme al cálculo de recursos disponibles. De esta manera, las jubilaciones dejaron de autofinanciarse en función de la recaudación media, para pasar a ser un rubro más dentro del Presupuesto General ${ }^{29}$.

En 'Chocobar' la Corte Suprema -durante la presidencia de Carlos Menemhabía ordenado que en el periodo comprendido entre el $1^{\circ}$ de abril de 1991 y el

27 La Nación, 30/03/2005. 'Miles de causas que sufririan menos espera'.

28 CSJN 'Sánchez, María del Carmen c/ ANSES s/reajustes varios', sentencia del 17 de mayo de 2005.

29 En función de esta última reforma, mediante decreto de necesidad y urgencia se sustituyó el AMPO (Aporte Medio Provisional Obligatorio) por el MOPRE (Módulo Previsional). Este módulo es una medida de valor estipulada anualmente por el Ministerio de Trabajo y Seguridad Social conjuntamente con el Ministerio de Economía y se fija de acuerdo con las posibilidades emergentes del Presupuesto General de la Administración Nacional para cada ejercicio. 
31 de marzo de 1995 se aplicara en total una movilidad del 13,8\%, porcentaje significativamente menor a la evolución real (entre 35\% y 45\%) de los salarios en dicho periodo. La corte entendió que la Ley de Convertibilidad había derogado el mecanismo de movilidad establecido por la Ley 18.037. Pese a ello, en 2005 la nueva conformación de la Corte decidió reexaminar la cuestión a raíz del reclamo presentado por la señora María del Carmen Sánchez, quien recurrió a la justicia solicitando la actualización de su jubilación por el tiempo correspondiente a los años 1991 a 1995. La demanda argumentaba que la ley 18.037 seguía vigente y que, por ende, su jubilación debía ser ajustada de acuerdo con la variación de los salarios de los trabajados activos durante el periodo en cuestión.

En contraste con el fallo 'Itzcovich', las implicancias políticas y económicas del caso de la Sra. Sánchez inquietaban al gobierno de Néstor Kirchner. Durante las semanas previas a la sentencia de la Corte Suprema, la posibilidad de que se revirtiera la doctrina de 'Chocobar' recibió una cobertura extensa por parte de los medios de comunicación ${ }^{30}$. Preocupada por las posibles consecuencias de una decisión adversa, la Administración Nacional de la Seguridad Social le envió un informe técnico a la Corte explicando el potencial impacto económico de un cambio de doctrina respecto a los mecanismos de movilidad de las jubilaciones ${ }^{31}$. Según el informe, la aplicación de una movilidad basada en la variación de los salarios de los trabajadores (el índice IGR) a los casos pendientes de resolución en el Poder Judicial implicaría un gasto anual adicional de 330 millones de dólares, sumado a otros 1.745 millones por pagos retroactivos. En caso de aplicarse el IGR a los reclamos de jubilados pendientes en sede administrativa (es decir, no judicializados aún) dichas cifras aumentarían a 1.300 y 3.300 millones respectivamente.

En el caso 'Sánchez' la Corte finalmente se expidió a favor de la movilidad de las jubilaciones durante el periodo 1991-1995. Sostuvo que si bien la Ley de Convertibilidad (23.928), vigente a partir de abril del año 1991, dispuso la prohibición de toda actualización de prestaciones dinerarias, la misma no era aplicable al cálculo de la movilidad de las jubilaciones vigente en aquel momento (artículo 53 de la ley 18.037). Alli se fijaba que la movilidad se debía determinar en función del índice de variación del nivel general de remuneraciones. La aplicación de dicho índice, según lo resuelto por la Corte, resultó en una movilidad del $44 \%$, un cambio significativo en relación con el anterior porcentaje de 13,8\% reconocido por el precedente 'Chocobar'32.

El fallo remarcó que la Constitución Nacional exige que las jubilaciones y pensiones sean móviles, aunque no establece un sistema o mecanismo especial

\footnotetext{
Clarín, 10/04/2005. 'Revisan un fallo de la mayoría automática menemista'.

Clarin, 30/04/2005. 'Una decisión que daría marcha atrás con una sentencia de la época de Cavallo'.

32 El voto de la mayoria (Petracchi, Belluscio, Fayt, Maqueda -según su voto-, Highton, Lorenzentti -según su voto-, y Argibay -según su voto-) sostuvo que no surge ni expresa ni tácitamente del régimen de convertibilidad la modificación de la reglamentación del art. 14 bis de la Constitución Nacional. De esta forma, dejó en claro su criterio respecto a que la Ley 23.928 no derogó la ley 18.037 y que, por ende, las garantías contenidas en esta última siguieron vigentes durante el periodo 1991-1995.
} 
para hacer efectiva dicha exigencia. En tal sentido, el tribunal entendió que es el legislador quien debe elegir el régimen tendiente a lograr la movilidad de las prestaciones previsionales garantizada por la Constitución. Sin embargo, se ocupó de aclarar que la Corte puede ejercer un control jurisdiccional posterior destinado a asegurar la razonabilidad de dicho régimen o a impedir que por medio de aquél se violen los derechos de los jubilados.

Si bien no hay datos oficiales, se calcula que el fallo benefició directamente a unos 1.000 jubilados cuyos juicios habían llegado hasta la Corte Suprema, los cuales obtendrían un reajuste en sus haberes del 44\% con retroactividad a abril de 1991. El impacto económico, incluyendo los pagos por retroactividad fue de alrededor de 28 millones de pesos, unos 28.000 pesos por jubilado, una cifra menor comparada con los 24.000 millones de pesos que la Administración Nacional de la Seguridad Social (en adelante ANSES) pagó ese año en concepto de jubilaciones y pensiones. Sin embargo, al momento de dictarse 'Sánchez' se estimaba que la sentencia podría beneficiar a otros 55.000 jubilados que tenían sentencias favorables de primera y segunda instancia, lo cual generaría erogaciones adicionales de aproximadamente entre 1.000 y 4.000 millones de pesos.

\subsection{LA VALIDEZ DE LOS REGÍMENES ESPECIALES DE JUBILACIÓN: 'GEMELLI'33}

En 1991 el Congreso aprobó el régimen jubilatorio docente por medio de la Ley 24.016. Dicho régimen establecía que el haber mensual del personal docente sería equivalente al 82\% móvil de la remuneración actualizada del cargo de mayor jerarquía que se hubiera desempeñado por un lapso no inferior a 24 meses. Las edades de jubilación fueron fijadas en 57 años para las mujeres y 60 años para los hombres, si tenían al menos 10 años al frente de alumnos. Sin embargo, a los pocos meses de haber sido aprobado, los docentes dependientes del Ministerio de Educación de la Nación fueron transferidos hacia las provincias en el marco de las reformas impulsadas por el ministro de economía Domingo Cavallo. Dichas reformas, entre otros aspectos, sacaron la educación secundaria de la órbita del gobierno nacional en favor de los gobiernos provinciales con el objetivo de mejorar la situación de las cuentas fiscales nacionales.

En 1994 el régimen jubilatorio docente fue derogado por el decreto 78/1994 del presidente Menem. Asimismo, los docentes de 11 provincias $^{34}$-al igual que el resto de los trabajadores- fueron transferidos nuevamente a la órbita nacional como parte del rescate de las cajas previsionales provinciales. A partir de entonces esos docentes pasaron a jubilarse por la ley general de jubilaciones, en lugar de hacerlo por el régimen específico de su actividad que le reconocía beneficios

34 Ciudades de Buenos Aires, Catamarca, Jujuy, La Rioja, Mendoza, Río Negro, Salta, San Juan, San Luis, Santiago del Estero y Tucumán. 
previsionales mucho más ventajosos, tales como el estándar del 82\% y el requisito de menos años de servicio.

En 2005, en el marco de su política de mejoras y aumentos a la clase pasiva, el presidente Néstor Kirchner resolvió poner nuevamente en funcionamiento el régimen especial de los docentes ${ }^{35}$, tanto para los maestros ya jubilados como para los activos ${ }^{36}$. Para tal fin restableció el parámetro del $82 \%$ para las jubilaciones docentes. Esto fue posible, en parte, por la superación de la crisis económica de 2001-2002 y la consecuente mejoría experimentada por la economía argentina. Sin embargo, no implementó la movilidad porque sostuvo que la misma había sido derogada por la Ley de Solidaridad Previsional.

La falta de actualización respecto a la aplicación el $82 \%$ móvil disminuyó notoriamente el monto de las jubilaciones docentes, que quedaron desfasadas respecto de los salarios de los maestros en actividad. En 2005 el reclamo llegó a la Corte Suprema. Una docente jubilada, la Sra. Esther Noemí Gemelli, presentó una demanda reclamando se actualizara su haber previsional conforme al régimen especial de los docentes ${ }^{37}$, aplicándose el estándar del 82\%. El gobierno, por intermedio de la ANSES, sostuvo que tanto el régimen especial de jubilaciones para el personal docente como el sistema de movilidad que garantizaba el $82 \%$ móvil habían sido derogados por la ley 24.24138.

En 'Gemelli' la Corte Suprema sostuvo que el régimen jubilatorio de los docentes establecido por la ley 24.016 se encontraba plenamente vigente ya que quedó sustraído de las disposiciones que integraban el sistema general reglamentado por las leyes 24.241 y 24.463. En decisión unánime, el Tribunal señaló que el régimen jubilatorio docente mantenía todas las características reconocidas por la ley 24.016, incluyendo la pauta de que el haber previsional docente debía ser equivalente al 82\% móvil de la remuneración mensual, porcentaje que el Estado debía asegurar, con los fondos que concurran al pago, cualquiera que sea su origen.

El aspecto más destacado de este fallo de la Corte Suprema es que confirmó la validez de los regímenes especiales de jubilación. Su importancia radica en el hecho que dichos regímenes contienen beneficios distintos -generalmente mayores- a los fijados por el régimen general de la Ley 24.241 y, por ende, otorgan mayores beneficios. En el caso del régimen de jubilaciones de los docentes, por ejemplo, se garantiza la pauta del $82 \%$ móvil.

\footnotetext{
Decreto 137/2005.

Artículos 129 y 168.

Por estar en un régimen especial, los docentes aportan al sistema jubilatorio 2 puntos más y a la vez no rige la rebaja jubilatoria que se aplica en las AFJP. Así los que están afiliados al Estado aportan el 13\% del sueldo (11\% general más $2 \%$ ) y los que están en una AFJP el $11 \%$ (9\% más 2\%) y a partir de octubre pasan al $13 \%$.

38 El ANSES argumentó que los arts. 129 y 168 de la ley 24.241 derogaron, entre otras, a la ley 24.016, tanto en lo referente a su régimen jubilatorio como a su sistema de movilidad, el cual sólo continuó practicándose por aplicación del art. 160 de la ley 24.241. Sostuvo además que ello se aclaró con la reglamentación del citado art. 168 mediante el decreto 78/94, y que si alguna duda subsistiera la cuestión quedó definitivamente resuelta a partir de la ley 24.463, cuyo art. 11 derogó el aludido art. 160.
} 
La trascendencia económica de 'Gemelli' radica en que al reconocer la vigencia de la movilidad del régimen especial de los docentes la Corte abrió las puertas a que otros maestros jubilados reclamaran el reajuste de sus haberes. En tal sentido, el fallo sentó un precedente aplicable no sólo a todos los docentes ya jubilados sino también a los 180.000 docentes activos que -en ese momento- estaban encuadrados sin la movilidad en el régimen docente de la mencionada ley. Esto incomodó a las altas esferas del gobierno de Kirchner. En un comunicado de prensa, la Secretaría de Seguridad Social reconoció su preocupación por el precedente debido a su potencial impacto en las cuentas fiscales del gobierno ${ }^{39}$. Por su parte, el Director de la ANSES, Sergio Massa, pidió responsabilidad a la Corte a la hora de fijar aumentos y advirtió que 'cualquier decisión que suponga aumentos para los pasivos debe ser acompañada por la determinación de cómo financiarlos en el tiempo ${ }^{40}$. Pero para los funcionarios del gobierno el verdadero problema, por su potencial impacto en el gasto, se produciría en el caso que los empleados públicos exigieran la aplicación de este precedente, ya que éstos gozaron del 82 por ciento móvil hasta diciembre de 2001 pero luego dejó de aplicarse ${ }^{41}$.

Sin embargo, las críticas del gobierno no afectaron la voluntad de la Corte, ya que en decisiones posteriores y aplicando principios análogos a los de 'Gemelli', el Tribunal ratificó la vigencia de otros regímenes especiales. En 'Siri' resolvió que correspondía la movilidad del $85 \%$ en los haberes jubilatorios de los funcionarios superiores del Servicio Exterior de la Nación, comprendidos en la ley especial 22.731. Posteriormente, en 'Massani de Sese' hizo lo propio en relación con el régimen de los investigadores, científicos y docentes universitarios con dedicación exclusiva (Ley 22.929).

\subsection{LA MOVILIDAD DE LAS JUBILACIONES A PARTIR DE 2002: 'BADARO’42}

Con su decisión en 'Sánchez' la Corte Suprema dio un paso trascendente para reparar la situación de los jubilados. En dicha oportunidad reconoció un ajuste del 35\% para las jubilaciones del sistema previsional general para el periodo comprendido entre los años 1991 y 1995, revirtiendo la doctrina del caso 'Chocobar' establecida por la Corte de los años noventa. Su importancia reside en que fijó un nuevo criterio respecto a los mecanismos de actualización aplicables a las jubilaciones durante el periodo que abarcaba desde la sanción de la Ley de Convertibilidad en 1991 hasta la sanción de la Ley de Solidaridad Previsional en 1995. Esta última norma había empeorado la situación de los jubilados, entre otras razones, debido a que eliminó los mecanismos de movilidad vigentes y dispuso que

Clarín, 9/08/2005. 'La Corte falló en favor del 82\% móvil en una jubilación'.

Página 12, 16/08/2005. 'Cruce entre el gobierno y la Corte por las jubilaciones'.

Clarin, 16/08/2005. 'La ANSES le pide a la Justicia prudencia en los fallos sobre jubilaciones'.

'Badaro, Adolfo Agustín c/ ANSES s/reajustes varios', sentencia del 8 de agosto de 2006. 
cualquier aumento a las jubilaciones debía ser fijado por el Congreso en forma anual en la Ley de Presupuesto ${ }^{43}$. Sin embargo, entre 1995 y 2005 dicho órgano no reconoció aumento alguno a los jubilados, postergando injustificadamente a toda la clase pasiva. En resumen, dado que 'Sánchez' sólo cubre los ajustes para el periodo 1991-1995, que las pautas de movilidad automática fueron derogadas por la Ley de Solidaridad Previsional, y que el Congreso no otorgó aumentos en más de una década, a partir de 1995 no había mecanismo legal alguno para actualizar las jubilaciones.

Al mismo tiempo, si bien el gobierno del presidente Néstor Kirchner otorgó sucesivos aumentos a los jubilados, éstos beneficiaron únicamente a aquellos con haberes menores a los $\$ 1.000$ pesos. Ninguno de los siete aumentos concedidos por decreto presidencial entre agosto de 2003 y septiembre de 2005 alcanzó a aquellos con haberes superiores a esa cifra. Los con jubilaciones por encima de ese límite no sólo no tuvieron aumentos desde 1995 sino que además se vieron perjudicados por el achatamiento de la pirámide previsional, ya que la política de dar aumentos sólo a quienes cobraban el haber mínimo provocó el engrosamiento de la base del sistema. De esa forma se quebró la proporcionalidad entre los mayores aportes realizados durante la vida laboral y el beneficio previsional actual, el cual se acerca cada vez más al mínimo. A modo ilustrativo, en el año 2002 quienes cobraban la jubilación mínima representaban el 17\% del total de jubilados. En agosto de 2003 esa situación había trepado al 53\%, y en junio de 2006 quienes cobraban el haber mínimo ya alcanzaban el 67\% de los 3.318 .866 jubilados existentes ${ }^{44}$.

La ausencia de un mecanismo efectivo para asegurar la movilidad de las jubilaciones a partir de 1995 dio lugar a la presentación de numerosas demandas. En 2006 la Corte evaluó el reclamo de Adolfo Agustín Badaro, quien se había jubilado como conductor naval en 1985. Dado que percibía una jubilación de \$1.144 pesos, no se vio beneficiado por aumento alguno durante más de una década. Frente a esa situación, recurrió a la justicia para que se actualizase su jubilación. La demanda señalaba que la sanción de las leyes $25.561^{45}$ y $25.565^{46}$ inició un proceso de acomodamiento de precios que haría posible la revisión del fallo 'Heit Rupp', donde el Tribunal había reafirmado la facultad del Congreso de la Nación para establecer aumentos a las prestaciones por medio de la Ley de presupuesto

$43 \quad$ El artículo 7 de la Ley 24.463 estableció que todas las jubilaciones del sistema previsional público tendrán la movilidad que anualmente determine el Congreso de la Nación en la Ley de Presupuesto, aclarando que en ningún caso esta movilidad podrá consistir en una determinada proporción entre el haber de retiro y las remuneraciones de los activos.

44 Otro $24,5 \%$-equivalente a 846.150 jubilados- cobraba entre $\$ 471$ y $\$ 1.000$, y el restante $8,5 \%$ -319.835 jubilados- percibía haberes mayores a \$1.000. Clarín, 10/5/2006 'Las diez claves para saber cómo queda el nuevo mapa jubilatorio'.

45 'Ley de Emergencia Publica y Reforma', sancionada el 6 de enero de 2002, que entre otras cosas derogó la Ley de Convertibilidad e introdujo reformas sustanciales al sistema cambiario.

46 Ley de Presupuesto General para la Administración Nacional para el ejercicio 2002, sancionada el 6 de marzo de 2002. 
anual, pero dejando abierta la posibilidad de declarar inconstitucional dicho mecanismo en caso que generase un perjuicio concreto a los jubilados.

La cuestión de mayor trascendencia en el reclamo de Badaro se relacionaba con la movilidad de las jubilaciones con posterioridad a la sanción de la Ley de Solidaridad Previsional (24.463), es decir, a partir del 31 de marzo de 1995, ya que en 'Sánchez' la Corte ya se había expedido con relación al periodo anterior a esa fecha. El Tribunal debía analizar si se podía aplicar algún tipo de movilidad a partir de 1995 y, eventualmente, fijar una fecha específica para la entrada en vigencia de un nuevo mecanismo.

En 'Badaro' la Corte resolvió que la ausencia de aumentos en las jubilaciones superiores a $\$ 1.000$ pesos no podía ser considerada resultado de un sistema válido de movilidad pues la finalidad de la garantía constitucional en juego era acompañar a las prestaciones en el transcurso del tiempo para reforzarlas a medida que decayera su valor con relación a los salarios de actividad. Pero, en lugar de determinar sin más el índice aplicable para la actualización, ordenó que se comunicase el contenido de la sentencia al Poder Ejecutivo Nacional y al Congreso de la Nación a fin de que, en un plazo razonable, éstos adoptasen las medidas necesarias para solucionar la situación ${ }^{47}$.

La sentencia entendió que si bien la Ley de Solidaridad Previsional estableció que es el Congreso quien tiene la facultad de otorgar los aumentos mediante la Ley de Presupuesto, sostuvo que la inacción del mismo no es aceptable ya que condujo a un deterioro en las jubilaciones, violando la movilidad garantizada por el art. 14 bis de la Constitución Nacional ${ }^{48}$. El Poder Legislativo -sostuvo la Corte- debe proceder a su reglamentación, la cual debe ser razonable y no puede desconocer el derecho de los beneficiarios a una subsistencia decorosa y acorde con la posición que tuvieron durante su vida laboral.

Con respecto a las medidas necesarias para remediar la situación, el Tribunal entendió que no le correspondía fijar sin más un mecanismo que diera respuesta al reclamo del Sr. Badaro, puesto que dicha tarea no está dentro de su jurisdicción sino que es facultad exclusiva del Congreso de la Nación. Por eso, en lugar de resolver qué movilidad aplicar al caso en cuestión, el tribunal dispuso poner en conocimiento de la situación al Congreso a fin de que resolviera el conflicto planteado de acuerdo con sus atribuciones.

En su decisión, la Corte realizó un pormenorizado análisis del ejercicio por parte del Congreso de su facultad de disponer aumentos en las jubilaciones y pensiones. En tal sentido, destacó que en el periodo comprendido entre 1995 y 2005 ninguna de las leyes de presupuesto ${ }^{49}$ incluyó disposición alguna con

47 Con relación al periodo comprendido entre el 31 de marzo de 1991 y 31 de marzo de 1995, la Corte resolvió que debía aplicarse la doctrina sentada en el caso 'Sánchez' y ordenó notificar a la ANSES para que dé cumplimiento a dicha parte del fallo. S.2758. XXXVIII, sentencias del 17 de mayo y 28 de julio de 2005 respectivamente.

48 En lo que respecta al reclamo de ajustes por el periodo comprendido entre 1991 y 1995, la Corte reafirmó lo resuelto en Sánchez.

49 Leyes $24.447,24.624,24.938,25.064,25.237,25.401,25.565,25.725,25.827$ y 25.967. 
relación a la movilidad de las prestaciones previsionales, ni tampoco eventuales explicaciones con relación a la imposibilidad de otorgar aumentos ${ }^{50}$.

El Tribunal evaluó además los importantes cambios en la economía acaecidos a partir de 2002, los cuales conllevaron variaciones importantes en todos los indicadores utilizados para analizar el mantenimiento o disminución del nivel de vida de los jubilados. El fallo destacó que a partir de 2003 se consolidó un proceso de recuperación de las variables salariales, que no se reflejó en un adecuado reconocimiento para la totalidad de las prestaciones jubilatorias. Si bien la Corte reconoció que el Poder Ejecutivo dispuso por decreto una serie de aumentos que indudablemente mejoraron las prestaciones previsionales, resaltó que dichos aumentos fueron sólo aplicables a quienes percibían haberes menores a \$1.000. Sin desconocer la emergencia que motivó los aumentos a quienes estaban en la parte inferior de la escala de haberes, la Corte indicó que dicha situación no podía convalidar una postergación indefinida de aquellos con haberes mayores.

Debe destacarse que en este fallo la Corte Suprema parece buscar un balance apropiado entre la protección del derecho a gozar de una jubilación móvil y el respeto por la separación de poderes ya que, por una parte, reconoció la existencia de una postergación injusta generada por la falta de mecanismos de movilidad para actualizar las jubilaciones y pensiones y, por la otra, entendió que para reparar ese daño era necesario tomar ciertas medidas, aunque éstas no eran de su competencia sino de los poderes legislativo y ejecutivo.

La decisión de la Corte Suprema denota mesura en cuanto a la forma de remediar la situación. En lugar de reparar ella misma los daños generados por la ausencia de un mecanismo de movilidad, le comunicó a los otros poderes del Estado que eran ellos quienes -en ejercicio de sus atribuciones constitucionales- debían intervenir para subsanar la situación. Asimismo, remarcó que dicha intervención debía llevarse a cabo en un 'plazo razonable', aunque sin dar mayores precisiones. Esto resultó un gesto prudente que parecía destinado a evitar fricciones con los demás poderes. El tribunal bien podría haber aceptado el reclamo de Badaro y reconocerle sin más la actualización de su jubilación en un determinado porcentaje. Dicha solución era más costosa en términos institucionales, ya que el Poder Legislativo podría haberla acusado de usurpar sus facultades e intentar castigarla, por ejemplo, mediante un proceso de juicio político. Sin embargo, la fórmula de la sentencia sugiere que la Corte consideró más apropiado que fuera el Congreso quien -haciendo uso de sus facultades constitucionales- remediara la situación.

Asimismo, la mera instrucción dada al Congreso para que solucionara el problema de la movilidad era de por sí inquietante dados los patrones históricos en

50 Todos los aumentos otorgados por el presidente Kirchner a los jubilados fueron efectuados mediante Decretos, es decir, por órdenes dictadas por el Poder Ejecutivo. Entre 1995 y 2006 las leyes anuales de presupuesto no incluyeron previsiones relacionadas con aumentos para la clase pasiva, ni tampoco explicaciones o justificaciones sobre la ausencia de aquéllos. Con este argumento, lo que la Corte pareciera estar poniendo de manifiesto es tanto la inacción del Congreso en materia de ajustes como la inexistencia de un mecanismo automático para la actualización de las jubilaciones. 
la relación entre ambos poderes ${ }^{51}$, seguramente por eso la sentencia evitó fijar un plazo concreto. Sin embargo, como se verá a continuación, el poder legislativo no tomó a tiempo las medidas sugeridas por la Corte Suprema. Si bien en cierta medida reaccionó frente al pedido del tribunal, no lo hizo en la forma esperada. En lugar de crear un mecanismo para garantizar la movilidad de las prestaciones previsionales, el Congreso sólo otorgó un aumento fijo del 13\% para todos los jubilados ${ }^{52}$.

El fallo 'Badaro' no fue sensible sólo en términos político-institucionales, también lo fue desde un punto de vista económico. En caso de hacer una aplicación extensiva del mismo a todos los jubilados, su dimensión financiera adquiere una inesperada relevancia. Algunas estimaciones indicaban que si el gobierno intentara recompensar a todos los jubilados por la postergación sufrida desde 2002, el costo fiscal ascendería a $\$ 9.500$ millones -casi un punto del PBI-, siempre que el criterio utilizado para el ajuste fuera la variación del índice general de salarios (IGR). En cambio, si se intentara compensar el deterioro en el poder de compra de las jubilaciones entre 2002 y 2006 el costo ascendería a \$22.500 millones $^{53}$.

Sin dudas, el anuncio de 'Badaro' generó un profundo impacto político ya que la Corte Suprema exhortó a las otras ramas del gobierno a resolver un tema políticamente sensible ${ }^{54}$. Además, el tribunal requirió que la solución tuviera lugar dentro de un 'plazo razonable'. En una entrevista, el Presidente de la Corte Suprema, Ricardo Lorenzetti, dijo expresamente que la respuesta por parte del Congreso debía acontecer a la brevedad, y sostuvo que "es urgente, hay un derecho violado" 55 .

51 La historia de las relaciones entre la Corte Suprema y el Poder Legislativo no registra episodios en los cuales aquélla le haya impuesto a este último obligaciones, mandatos o instrucciones concretas para modificar aspectos sustantivos de una política pública determinada. Nunca antes el tribunal -en sus conformaciones anteriores- había efectuado una manifestación de tal calibre, que implicara poner en marcha los mecanismos de generación de normas previstos por la Constitución. La exhortación realizada por la Corte al Congreso en la sentencia del caso Badaro contenía la sugerencia explícita de que éste actuara, es decir, le pedía nada menos que pusiera en marcha el proceso legislativo, que sesionara y eventualmente dictara una ley. La solicitud, además, no era una mera invocación general o vaga, sino que estableció el requisito de que la respuesta del Congreso ocurriera en un "plazo razonable". Si bien la expresión utilizada era ambigua, como se verá posteriormente, transcurrido cierto tiempo la Corte consideró que su mandato había sido desoído y procedió a fijar un porcentaje de ajuste para la jubilación de Badaro.

52 Vale mencionar que el remedio dispuesto en 'Badaro' coincide con algunas otras decisiones recientes de la Corte Suprema, por las cuales se ordenó a los demás poderes del Estado a tomar ciertas medidas o adoptar ciertas conductas. En 'Rozas', por ejemplo, el Tribunal declaró inconstitucional el régimen de subrogancias de jueces y ordenó al Congreso que en el plazo de un año diseñara un nuevo mecanismo acorde a una serie de parámetros fijados en la sentencia.

53 Esa suma equivalía al superávit primario esperado para 2006 y no considera el costo de los aguinaldos ni las pensiones no contributivas. Ecolatina, 'El Costo del Ajuste'. Disponible en http://www.ecolatina.com.ar

54 Página 12, 9/08/2006. 'Un blindaje al bolsillo de los abuelos'. La Nación, 9/8/2006. 'La Corte ordenó otorgarles movilidad a las jubilaciones'. Clarín, 9/8/2006. 'La Corte ordenó al Congreso que debe actualizar las jubilaciones'. La Nación, 10/08/2006. Justicia para los jubilados.

55 Página 12, 10/08/2006. 'El plazo para actualizar las jubilaciones según Lorenzetti'. 


\subsection{LA FALTA DE RESPUESTA ADECUADA DEL CONGRESO: 'BADARO II'56}

Al poco tiempo de ser hecho público el fallo 'Badaro', el gobierno reaccionó anunciando un aumento del 13\% para jubilados y pensionados del sistema nacional de previsión social. El mismo se instrumentaría por medio de la Ley de Presupuesto para el 2007 y se haría efectivo a partir de enero de ese año. ${ }^{57} \mathrm{El}$ haber mínimo pasaría de $\$ 470$ a $\$ 530$ más -en algunos casos- el subsidio de $\$ 30$ del PAMI. El ajuste alcanzó a 4.244 .741 personas, incluyendo a los jubilados y pensionados pertenecientes al sistema de reparto, los beneficiarios del régimen de capitalización (sólo por el componente de financiación pública de sus haberes), los excombatientes de las Malvinas, y quienes cobran pensiones no contributivas. Sergio Massa, entonces Director del ANSES, especificó que haría falta una partida presupuestaria adicional de $\$ 4.100$ millones para hacer frente a dicho aumento ${ }^{58}$.

A pesar de que la medida del gobierno fue bien recibida por la clase pasiva, la Ley de Presupuesto de 2007 no incluyó un verdadero mecanismo para fijar la movilidad de las prestaciones previsionales ya que determinó, por ejemplo, que las jubilaciones debían seguir la evolución de los salarios o de la recaudación. Sólo incluyó un aumento fijo y generalizado para todos los beneficiarios del sistema nacional de previsión social ${ }^{59}$.

Transcurrido más de un año desde su pronunciamiento original, la Corte Suprema analizó nuevamente la situación del caso para verificar si se había dado cumplimiento a lo dispuesto en la misma. En dicho contexto, la Corte se volvió a pronunciar sobre el caso Badaro en una sentencia ampliatoria y declaró la inconstitucionalidad del art. 7, inc. 2, de la ley 24.463 porque en su aplicación práctica no se había cumplido con el mandato del art. 14 bis de la Constitución Nacional que garantiza la movilidad de las jubilaciones, disponiendo un ajuste en su jubilación para el periodo comprendido entre el 1 de enero de 2002 y el 31 de diciembre de 2006 según las variaciones anuales del índice de salarios (nivel general), elaborado por el Instituto Nacional de Estadísticas y $\operatorname{Censos}^{60}$. En la práctica, ello representa un incremento del 88,5\%.

56

57

58 fondos genuinos del sistema previsional, dado que los ingresos de la ANSES vienen creciendo más del
$40 \%$, lo que permite contar con recursos ya ahorrados para financiar este aumento. Clarí, 9/9/2006 'Para pagar la suba harán falta $\$ 4.100$ millones'.

59 Dado que el aumento consistió en un porcentaje similar para todas las escalas jubilatorias, no modificó en nada el fenómeno del achatamiento de la pirámide jubilatoria. El 70\% de los 3.591 .006 beneficiarios seguirá cobrando la jubilación mínima. En septiembre de 2002, los que cobraban la mínima eran el 17\% del padrón. En agosto de 2003 el 53\% ya estaba en esta situación. Y así hasta llegar al 70\% en junio de 2006. A partir de enero de 2007 el haber medio del sistema fue de 653 pesos, equivalente a casi el $40 \%$ del sueldo medio de los trabajadores registrados. Clarin, 9/9/2006 'Las claves del aumento del 13\% para los jubilados y pensionados'.

60 Del fallo se desprende que la razón por la que la Corte ordenó el ajuste por movilidad sólo para el periodo 2002-2006 radica en que en dicho periodo hubo aumentos en los salarios y al mismo tiempo el país experimentó un proceso sostenido de recuperación económica. Cabe recordar que la movilidad 
Al momento de dictar sentencia la Corte efectuó un repaso de las medidas tomadas por el Congreso y el Poder Ejecutivo desde su sentencia anterior en el caso. El tribunal reconoció que la ley de presupuesto de $2007^{61}$ incluyó una serie de disposiciones relacionadas con el ámbito previsional. Por ejemplo, dispuso un aumento del 13\% para todos los jubilados -incluso para los de haberes más altosa partir del $1^{\circ}$ de enero de 2007; fijó el haber mínimo en la suma de $\$ 530$ pesos; y autorizó al gobierno a conceder en el curso del año aumentos adicionales siempre que las finanzas públicas lo permitieran ${ }^{62}$. Cabe destacar que éste fue el primer aumento concedido por el Congreso a los jubilados desde la aprobación de la Ley de Solidaridad Previsional en 1995.

Sin embargo, la Corte concluyó que las medidas adoptadas por la mencionada ley no fueron aquellas reclamadas en su sentencia del 8 de agosto de 2006. En primer lugar, señaló que el aumento del $13 \%$ es aplicable a toda la clase pasiva, sin tener en cuenta la cuestión del achatamiento de la escala de haberes destacado por el tribunal ${ }^{63}$. En segundo lugar, destacó que la Ley 26.198 no hizo sino convalidar las normas que generaron el mencionado achatamiento ${ }^{64}$. Finalmente, la Corte entendió que la citada ley no resolvió -tal como había reclamado el tribunal en su anterior sentencia- el problema de la ausencia de mecanismos para determinar la movilidad de las prestaciones previsionales.

A la luz de las consideraciones anteriores y estimando agotado el 'plazo razonable' otorgado a los poderes Ejecutivo y Legislativo, la Corte analizó la validez del mecanismo de movilidad del artículo 7 inciso 2 de la Ley 24.463. El tribunal sostuvo que dicha norma derogó los mecanismos de movilidad existentes al momento de su sanción pero encomendó al Congreso la delicada misión de establecer anualmente pautas que asegurasen a los jubilados y pensionados el mantenimiento de un nivel de vida acorde con la posición que tuvieron durante sus años de trabajo. Resaltó, además, que no sólo era facultad sino también deber del Congreso fijar el contenido concreto de la garantía en juego, pero que dicho mandato no fue cumplido en las oportunidades y con el alcance previsto por el artículo 14 bis de la Constitución Nacional.

no es un mecanismo de ajuste por inflación sino que busca preservar una proporción entre los salarios de los trabajadores activos y las jubilaciones. Entre 1995 y 2001 la tasa de inflación fue muy baja y los salarios se mantuvieron estables. Al mismo tiempo, el reclamo de Badaro hace referencia al deterioro de las jubilaciones a partir de 2002. Por lo tanto, hasta el momento la Corte no se había pronunciado expresamente respecto a si era aplicable algún tipo de ajuste por movilidad para el periodo 1995-2001.

61 Ley 26.198, Presupuesto de Gastos y Recursos de la Administración Nacional para el ejercicio 2007, sancionada el 13 de diciembre de 2006.

62 Eventualmente el gobierno dispuso un aumento del 12,50\% a partir del 1/9/2007 (Decreto 1346/07).

63 El único aumento para haberes mayores a $\$ 1.000$ fue otorgado en 2006 por el Decreto 764/06, pero según la Corte su magnitud no guarda relación con la disminución evidenciada en la causa.

64 El artículo 48 de la Ley 26.198 indica: 'Convalídanse los aumentos en las prestaciones mínimas dispuestos en los Decretos 391 de fecha 10 de julio de 2003; 1194 de fecha 4 de diciembre de 2003; 683 de fecha 31 de mayo de 2004; 1199 de fecha 13 de septiembre de 2004; 748 de fecha 30 de junio de 2005; y 764 de fecha 15 de junio de 2006; el suplemento por movilidad establecido en el Decreto $N^{\circ} 1199 / 04$, y el incremento general de las prestaciones del Régimen General dispuesto por el Decreto $N^{\circ} 764 / 06$ '. 
Asimismo, el tribunal analizó la evolución de los indicadores económicos en el periodo 2002-2006 y destacó que frente a las subas del 91,26\% en el nivel de precios y modificaciones del $88,57 \%$ en los salarios (según datos del INDEC), la jubilación del Sr. Badaro sólo se modificó en el mismo lapso en un $11 \%$ gracias al aumento dispuesto por el decreto 764/06, claramente insuficiente para reparar el deterioro sufrido. Dicha postergación, sin embargo, no guardaba correlación con la mejora en las cifras públicas de la recaudación y del balance fiscal. Por ello consideró que su haber debía ajustarse por el índice de variación de los salarios elaborado por el INDEC.

Tal como la propia Corte se preocupó por aclarar, los efectos de su resolución no se extendían directa y automáticamente a la numerosa cantidad de pleitos análogos en trámite ante el tribunal, sino que sólo se aplicaban al caso del Sr. Badaro. En ese sentido sostuvo que contribuiría a dar mayor seguridad el dictado de una ley que estableciera pautas de aplicación permanentes, indicando que ello permitiría además reducir la litigiosidad en la materia, fenómeno que había afectado el adecuado funcionamiento de Poder Judicial y redundado en un menoscabo de los derechos de los justiciables. Una vez más la Corte recordó la necesidad de contar con un tratamiento legislativo adecuado de la figura de la movilidad para evitar un uso excesivo de la vía judicial y brindar una mayor seguridad a los beneficiarios previsionales.

La potencial aplicación del precedente sentado en 'Badaro' al alto número de reclamos similares pone de relieve la dimensión económica del fallo. Cabe recordar que además de actualizar en $88,5 \%$ la jubilación, la Corte ordenó también el pago de la retroactividad más los intereses. Según estimaciones, existen entre 50.000 y 70.000 juicios iniciados por jubilados en todo el país que reclaman la movilidad o reajuste de sus haberes ${ }^{65}$. En estos casos, los tribunales inferiores deben aplicar el criterio sentado por la Corte en el caso 'Badaro'.

Al mismo tiempo, existe un altísimo número de jubilados que no han sido beneficiados por un reajuste aún, o que han obtenido uno menor al fijado por la Corte Suprema. En esa condición se encontrarían alrededor de un millón de personas. Según estimaciones, de los 6.000 juicios por año que, en promedio, se iniciaron entre 2003 y 2005, en 2006 trepó a 15.167 y se esperaba que superase los 20.000 en $2007^{66}$. El impacto de 'Badaro' puede evaluarse también en función de los fondos necesarios para hacer frente a las demandas. La Ley de Presupuesto para el año 2008 previó una partida de \$ 1.040 millones para atender en efectivo las sentencias a favor de los jubilados, y bonos por el equivalente a 903 millones de pesos por las retroactividades.

En relación con el valor de 2001, el Gobierno ajustó en varias oportunidades la jubilación mínima: en sus cuatro años de gestión (2003-2007) Kirchner la llevó de 150 pesos a 596 pesos. Esto benefició al 1,5 millón de jubilados que entonces

65 Diario Clarín, 'Llegan a 72.000 los juicios de jubilados que piden reajustes' 4/12/2007.

66 Diario Clarín, 'Aluvión de consultas jurídicas de jubilados que reclaman un ajuste' 12/12/2007; 'Más de un millón de jubilados podrían reclamar ajuste de haberes' 28/11/2007. 
ganaban menos de 300 pesos. En esos casos, sus haberes crecieron tanto o más que la inflación. Pero el resto de los jubilados no tuvo la misma suerte. Quien ganaba \$ 1.000 en diciembre de 2001, en 2007 percibía 1.411 pesos, porque tuvo sólo tres ajustes en todo este tiempo: 11\%, 13\% y 12,5\%. En cambio, de aplicarse el criterio del fallo Badaro ese haber en 2007 debería haber sido de $\$ 2.397$ pesos.

Por último, cabe señalar que la Corte Suprema logró instalar el tema en la agenda política. Como producto directo de la sentencia en 'Badaro', en octubre de 2008 el Congreso de la Nación aprobó finalmente un mecanismo para asegurar la movilidad de las jubilaciones. La ley contempla dos aumentos por año para los haberes jubilatorios, permitiendo un mecanismo de ajuste automático en función de la evolución de los salarios de los trabajadores y la recaudación previsional. Al incluir ambos componentes se asegura que los haberes jubilatorios seguirán la evolución de los salarios, a la vez que acompañarán el aumento de los ingresos al Sistema Previsional. La actualización se llevará a cabo dos veces al año, en marzo y septiembre.

Este caso no constituyó exactamente un revés para las preferencias en materia previsional del gobierno de Néstor Kirchner y de su sucesora Cristina Fernández de Kirchner. La sentencia de la Corte y la posterior sanción de una ley de movilidad automática forzaron al Poder Ejecutivo -que de hecho había otorgado numerosos aumentos a los jubilados- a adaptar la implementación de su política de acuerdo a las reglas y mandatos constitucionales. El Poder Ejecutivo ya no puede otorgar aumentos a las jubilaciones de manera arbitraria, sino que debe respetar el nuevo marco legal que impone que los ajustes se realicen de manera automática dos veces al año. Por cierto, esto impide, por ejemplo, que se haga un uso electoral de los aumentos, algo que pareciera haber sido el caso durante la administración Kirchner ${ }^{67}$. Además, bajo el nuevo sistema los aumentos deben beneficiar a todos los jubilados y no como en el pasado sólo a quienes percibían el haber mínimo.

\subsection{EL ACCIONAR DE LA CORTE SUPREMA Y EL CONTEXTO INSTITUCIONAL}

Los fallos descritos precedentemente produjeron cambios sustanciales en la política pública previsional argentina. Los mismos tuvieron un impacto directo en el reconocimiento y protección de los derechos previsionales de los trabajadores, lo que, a su vez, generó las consecuentes cargas financieras sobre el sistema previsional. Como consecuencia de la eliminación de la instancia de apelación ordinaria se redujeron los plazos de tramitación de los casos y se acortaron los tiempos para

67 Si el Poder Ejecutivo tiene la facultad de otorgar aumentos a las jubilaciones por decreto, cada vez que lo haga puede obtener beneficios, como por ejemplo aumentar su nivel de popularidad entre los jubilados. En cambio, si la actualización de las jubilaciones se realiza mediante un mecanismo automático establecido por ley, el gobierno ya no puede otorgarlos y por ende no habría posibilidades de que obtuviera rédito alguno. 
exigir al Estado el pago de las sentencias. Asimismo, el reconocimiento de la vigencia de la movilidad entre 1991 y 1995 ('Sanchez') y entre 2002 y 2006 ('Badaro') obligó al Estado a pagar la diferencia correspondiente a miles de jubilados. Finalmente, la sanción por parte del Congreso de un mecanismo de movilidad automática para el ajuste periódico de las jubilaciones impuso una carga adicional al Estado y redujo la discrecionalidad para otorgar los aumentos.

La magnitud de los derechos reconocidos por la Corte, al igual que los cambios generados por sus sentencias en la política pública previsional, podría llevarnos a pensar que se trata de un tribunal sumamente activo, que reconoce derechos sin miramientos a sus consecuencias para el sistema previsional, para las finanzas del Estado, o para su sostenibilidad en el tiempo. Se podría incluso sostener que la Corte fue el motor de cambios sustanciales en la política previsional, y que sus iniciativas desafiaron las preferencias del Poder Ejecutivo en este tema. Sin embargo, para poder comprender la real dimensión de las acciones de la Corte Suprema es preciso tomar en cuenta el contexto económico y político en las que ellas ocurrieron.

Luego del colapso financiero del 2001-2002, Argentina retornó gradualmente a la senda del crecimiento. Los indicadores macroeconómicos para el periodo 2003-2007 muestran una marcada recuperación, no sólo en relación con la evolución del PBI y la actividad económica ${ }^{68}$ sino también en relación con la disminución del desemple ${ }^{69}$, la pobreza y la indigencia ${ }^{70}$. Asimismo, y por primera vez en décadas, las cuentas públicas exhibieron un superávit genuino. Por ejemplo, el año fiscal 2007 cerró con un superávit de $\$ 25.670$ millones de pesos, lo que equivale al 3,2\% del $\mathrm{PBI}^{71}$.

68 La actividad económica creció alcanzando una expansión que hacía tiempo no registraba. Por ejemplo, algunos índices representativos del aumento de la actividad económica entre 2003 y 2007 son el crecimiento de la industria (pasó de 90,3 a 125,8 millones de pesos), la construcción (pasó de 79,6 a 134,3 millones de pesos), las exportaciones (pasaron de 35.109 a 50.866 millones de pesos) y la inversión total (pasó de 36.660 a 80.940 millones de pesos). Informe de la Fundación Capital, disponible en http:// www.fcapital.com.ar/home.php.

69 En relación con el mercado laboral, el desempleo descendió en más de un tercio durante el periodo 2003-2007. En el primer trimestre de 2007 la tasa de desempleo se encontraba en el 9,8\% mientras que en el primer trimestre de 2003 era del 20,4\%. También se contrajo de manera significativa la subocupación: mientras que en el primer trimestre de 2003 era de 17,7\%, en el primer trimestre de 2007 fue de 9,3\%. CELS. Derechos Humanos en Argentina. Informe Anual 2008.

70 Según un informe de SEL Consultores, desde 2003 en adelante aumentó el empleo y disminuyeron las tasas de desempleo, lo que generó un impacto positivo sobre los índices de pobreza e indigencia, que también fueron en baja. Así, los índices de desocupación en 2007 demostraban una baja de 1.500.000 desempleados desde el 2003 y un traslado de 700.000 personas desde los planes sociales a empleos. Además se crearon aproximadamente 3.000.000 de nuevos empleos. Newsletter SEL Consultores, diciembre 2007, disponible en http://www.selconsultores.com.ar/newsletter/diciembre-2007.pdf Para la CEPAL, a fines de 2006, el desempleo se ubicó por debajo del 9\% debido al incremento de la producción agregada. Anelló, Guillermo; Kosacoff, Bernardo y Ramos, Adrián, 'Crisis, recuperación y nuevos dilemas ', óp. cit. De acuerdo con el informe de la Fundación Capital, en 2003 la tasa de desempleo (sin incluir el Plan Jefes y Jefas) era de un 22\% y en 2007 de un 9,5\%, por lo que disminuyó en un 56,8\%. Disponible en http://www.fcapital.com.ar/home.php.

71 Anuncio del ex Ministro de Economía, Martín Lousteau, en Casa de Gobierno, el 15 de enero de 2008. Disponible en http://www.casarosada.gov.ar/index.php?option=com_content\&task=view\&id=1560 
La incidencia de la Corte Suprema de Justicia en la formulación de políticas públicas...

\section{CUADRO 3}

Porcentaje de crecimiento del PBI (2003- 2007).

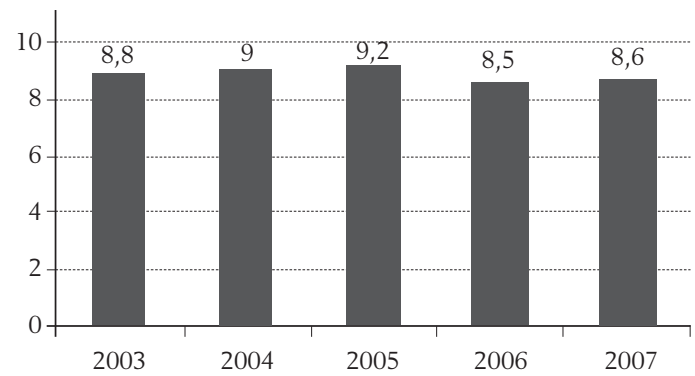

Fuente: CEPAL. Anuario estadístico de América Latina y el Caribe (2007).

CUADRO 4

Superávit fiscal primario

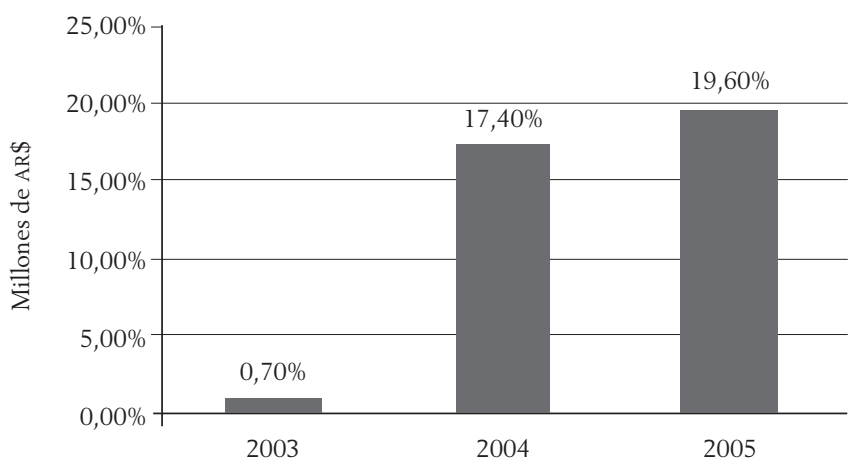

Fuente: Ministerio de Economía.

La notoria recuperación macroeconómica coadyuvó a la implementación de cambios sustanciales en la política previsional del gobierno. Los jubilados y pensionados, que habían sido uno de los sectores más postergados durante la década de 1990 y más afectados por la crisis financiera del 2001-2002, pasaron a ser una de las prioridades de la política social del presidente Kirchner. Esto se manifestó en acciones claras y concretas por parte del Presidente en beneficio de la clase 
pasiva. Entre julio de 2003 y septiembre de 2007, el Poder Ejecutivo dispuso nueve aumentos a la pensión mínima, la cual se incrementó de $\$ 150$ a $\$ 596$. Esto representó un cambio radical en materia de política previsional ya que entre 1995 y 2003 no se había otorgado ningún tipo de aumentos.

\section{CUADRO 5}

Aumento a las jubilaciones durante la presidencia de Néstor Kirchner

\begin{tabular}{|c|c|c|c|c|}
\hline \multirow{2}{*}{ FECHA } & \multicolumn{2}{|c|}{ AUMENTO } & \multirow{2}{*}{ PENSIÓN MÍNIMA } & \multirow{2}{*}{ MECANISMO UTILIZADO } \\
\hline & EN \$ & $\%$ & & \\
\hline & & & $\$ 150$ & \\
\hline Jul-03 & 69 & $46 \%$ & $\$ 219$ & Decreto 391/03 \\
\hline Ene-04 & 21 & $9,6 \%$ & $\$ 240$ & Decreto 1194/03 \\
\hline Jun-04 & 21 & $8,8 \%$ & $\$ 261$ & Decreto 683/04 \\
\hline Ago-04 & 21 & $8 \%$ & $\$ 282$ & Decreto 683/04 \\
\hline Sep-04 & 27 & $9,6 \%$ & $\$ 309$ & Decreto 1199/04 \\
\hline Jul-05 & 42 & $13,6 \%$ & $\$ 351$ & Decreto 748/05 \\
\hline Sep-05 & 40 & $11,4 \%$ & $\$ 391$ & Decreto $1273 / 05$ \\
\hline Jun-06 & 79 & $20,2 \%$ & $\$ 470$ & Decreto 764/06 \\
\hline Ene-07 & 60 & $12,76 \%$ & $\$ 530$ & Ley de Presupuesto 2007 \\
\hline Sep-07 & 66 & $12,5 \%$ & $\$ 596,2$ & Decreto 1346/07 \\
\hline
\end{tabular}

Fuente: Elaboración propia.

Sin embargo, hasta 2006 la política de aumentos del gobierno no benefició a la totalidad de jubilados y pensionados sino sólo a aquellos que percibían el haber mínimo, que luego de los sucesivos aumentos representaban un $67 \%$ del total de beneficiarios. De esta forma, los jubilados con haberes superiores a $\$ 1.000$ pesos no recibieron ninguno de los siete aumentos dispuestos por el Presidente ${ }^{72}$. Para 2007 la Ley de Presupuesto estableció un mínimo jubilatorio de 530 pesos, y un aumento para los restantes jubilados del 13\%. El último aumento otorgado a los jubilados del Sistema Nacional de Previsión Social fue del 12,5\% en sus haberes en septiembre de 2007, medida que alcanzó a 4.924 .549 personas $^{73}$.

Por otra parte, el gobierno complementó su política de aumentos a los haberes previsionales con una política activa respecto al pago de sentencias judiciales

72 No fue hasta mayo de 2006 que aquellos con haberes de 1.000 pesos o más recibieron un aumento del $11,5 \%$, el primero desde 1992. Clarín, 10/5/2006, 'Jubilaciones: llevan a \$470 la mínima y suben $11 \%$ el resto'.

73 A raíz de esta disposición, el haber mínimo ascendió de 530 a 596,25 pesos, y el máximo pasó de 3.888 a 4.374 pesos. 
que ordenaban reajustes $\mathrm{u}$ otras medidas similares. A partir de 2004 las leyes de presupuesto incluyeron fondos para los pagos ordenados por el poder judicial y el ANSES realizó numerosos pagos de manera voluntaria. En 2007 la partida para cancelar sentencias insumió 1.505 millones de pesos (597 millones se cancelaron en efectivo y los otros 908 millones en bonos del Estado $)^{74}$. Por su parte, en el presupuesto del año 2009 se destinaron 2.343 millones para el pago de sentencias en juicios contra el Estado por mala liquidación de haberes. Según datos oficiales, durante 2008 se cancelaron unas de 25.000 sentencias contra el Estado en materia previsional y en 2009 se haría lo propio con otras $40.000^{75}$. Luego de la sentencia en 'Itzcovich', el ANSES incluso anunció que desistiría de la práctica por la cual todos los fallos adversos al Estado eran automáticamente apelados ${ }^{76}$.

En síntesis, las sentencias de la Corte fueron dictadas en un contexto económico favorable, con un marcado crecimiento del PBI y una evolución positiva de los principales indicadores económicos (empleo, actividad económica, exportaciones, etc.). El crecimiento del PBI y del empleo, en especial, tuvo un impacto positivo sobre el sistema previsional. Por su parte, el gobierno del presidente Kirchner alentó de manera sostenida la mejora de los ingresos de la clase pasiva. La cantidad y calidad de los aumentos otorgados por medio de decretos presidenciales confirman sus preferencias en materia de política previsional. Si bien es posible que el Poder Ejecutivo prefiriera mantener el control de la agenda de cambios en el sistema previsional y por ende las sentencias de la Corte no fueran de su total agrado ya que le quitaban protagonismo político, los fallos del máximo tribunal iban en sintonía con las preferencias del gobierno. El presidente Kirchner mostró una decisión sostenida de actualizar las jubilaciones (especialmente las de aquellos que recibían el haber mínimo) y de pagar los juicios previsionales contra el Estado.

\section{Conclusión}

Entre 2005 y 2007 la Corte Suprema se involucró de manera activa en el diseño e implementación de la política previsional. Sus sentencias contribuyeron a generar cambios concretos en la forma en que el Poder Ejecutivo -a través de las agencias correspondientes- despliega y articula sus acciones en dicho campo. E1 primer cambio producto de las sentencias de la Corte Suprema a partir de 2005 consistió en la eliminación de la apelación ordinaria en materia previsional ante la Corte Suprema. Al declararlo inconstitucional, el Tribunal dio una clara señal respecto no sólo a la ilegalidad de la apelación ordinaria sino también respecto a todo mecanismo que tuviere por objetivo retrasar el pago de las sentencias y evitar la reparación de la violación de derechos. Si bien los efectos de la sentencia en

74 Clarín, 21/01/2008. 'El Estado pagará este año \$ 1.943 millones por los juicios de jubilados'.

75 Clarín, 6/10/2008. 'El Gobierno pagará en efectivo 40.000 sentencias a jubilados'.

76 La Nación, 25/04/2005. 'Piden paciencia a los que ganaron juicios'. 
el caso Itzcovich se aplican sólo a dicha causa, inmediatamente el Congreso dictó la ley 26.025 que eliminó por completo la apelación ordinaria del sistema legal argentino. La intervención del máximo tribunal fue decisiva, ya que si bien el Congreso estaba considerando el tema desde hace tiempo, lo venía postergando indefinidamente. La supresión de la apelación ordinaria cambió por completo los tiempos de tramitación de los reclamos judiciales en sede judicial y contribuyó a que miles de sentencias de segunda instancia quedaran firmes, sin tener que recurrir a la Corte Suprema.

El segundo cambio se relaciona con el reconocimiento de la vigencia de los regímenes especiales de jubilación. En la práctica, esto significó que las jubilaciones de los trabajadores de ciertos sectores (por ejemplo, maestros, científicos, y jueces) volvieron a gozar de mejores beneficios tal como lo estipulaba la ley pero que habían sido considerados derogados tanto por el Poder Ejecutivo como por la Corte Suprema durante la década de 1990. A partir de la sentencia en el caso 'Gemelli', el Poder Judicial reconoció sistemáticamente la vigencia de los beneficios diferenciados para ciertos sectores, y posteriormente así lo hizo el gobierno.

El tercer cambio relevante se refiere a la movilidad jubilatoria. Como se explicó anteriormente, entre 1995 y 2005 el Congreso no incluyó en las respectivas leyes de presupuesto fondos destinados para hacer efectiva la movilidad de las jubilaciones, es decir, para ajustarlas de acuerdo a las variaciones de los salarios de los trabajadores activos. Por un lado, en el caso 'Sanchez', la actual composición de la Corte Suprema reconoció porcentajes más altos para la actualización de las jubilaciones que aquellos otorgados por la anterior composición. Por otro lado, en las dos sentencias del caso 'Badaro' la Corte no sólo puso de manifiesto la ilegalidad producto de la inexistencia de un mecanismo que asegure de manera efectiva la garantía de la movilidad de las prestaciones previsionales, sino que además exhortó al Congreso y al Poder Ejecutivo a que tomaran las medidas necesarias para remediar la situación. El accionar del máximo tribunal puso el tema de la movilidad jubilatoria en la agenda política, obteniendo una amplia cobertura por parte de los medios de comunicación. Veintiséis meses luego de la última sentencia de la Corte sobre este tema y luego de extensas discusiones legislativas, el Congreso de la Nación aprobó un nuevo régimen para asegurar la movilidad automática y efectiva de los beneficios de la seguridad social. El debate iniciado por la Corte en el caso 'Badaro', sumado a su requerimiento a los otros poderes del Estado para que adoptaran las medidas necesarias para garantizar la movilidad de las jubilaciones, culminó con la aprobación un nuevo marco regulatorio aprobado por el Congreso.

Por otra parte, la sentencia en el caso 'Badaro' marcó un cambio respecto a los patrones históricos de relación entre el Poder Judicial y el Poder Ejecutivo. La exhortación a los otros dos poderes del Estado a que tomaran medidas para remediar el problema de la movilidad generó sorpresa y confusión. En un sistema político notoriamente hiperpresidencialista, el Congreso no se ha caracterizado por tomar la iniciativa en este tipo de cuestiones, especialmente cuando su accionar pudiera tener consecuencias negativas para las preferencias del Poder Ejecutivo. 
Tradicionalmente, ha sido el Presidente quien ha impulsado cambios sustantivos en las áreas clave de las políticas públicas. Sin embargo, a partir de 2005 la Corte Suprema ha tomado un mayor protagonismo en la escena política en casos donde la violación de derechos requería un accionar expedito, como por ejemplo en materia de sobrepoblación carcelaria ${ }^{77}$, acceso a la vivienda y a servicios de salud ${ }^{78}$, y a reparación del medio ambiente ${ }^{79}$.

Todas las decisiones de la Corte analizadas en este trabajo influyeron en diversa medida a generar cambios en la política previsional. Individualmente, cada una de las sentencias tuvo un impacto específico positivo. Sin embargo, valoradas en conjunto, la intervención del Tribunal adquiere características inusitadas ya que logró desarticular los pilares básicos de la política previsional vigente desde mediados de la década de 1990 y generó nuevos parámetros para el funcionamiento del sistema. Algunos de los cambios gestados por la Corte incluso obtuvieron reconocimiento legislativo y se vieron reflejados en nuevas regulaciones legales. Vale decir que el efecto de las sentencias del Tribunal no sólo se limitó a cada uno de los casos en que fueron dictadas sino que eventualmente se aplicó a un universo de beneficiarios más extenso.

En relación con los otros poderes del Estado, la Corte contradijo u obstaculizó, en gran medida, las preferencias del Presidente en materia previsional. Si bien la administración del presidente Kirchner había demostrado un genuino interés en mejorar la situación de los jubilados, en repetidas oportunidades sus funcionarios hicieron pública su preocupación por los fallos del máximo tribunal. La Corte no bloqueó la política de aumentos a la clase pasiva del Poder Ejecutivo pero impuso importantes restricciones que limitaron su discrecionalidad (por ejemplo, que los aumentos no se restrinjan sólo a quienes perciban la jubilación mínima y que la movilidad se determine mediante un mecanismo automático plasmado por ley, entre otros) y logró que se modificaran algunos aspectos centrales de la política previsional.

En tal sentido el gobierno no recibió con agrado el accionar de la Corte ya que le impuso cambios o restricciones a los ejes sustantivos de su política pública previsional. Más aún, en algunos casos las sentencias del máximo tribunal incomodaron notoriamente al Poder Ejecutivo ya que conllevaban una mayor carga fiscal para el Estado. Al reconocer la Corte mayores porcentajes de ajustes para ciertas jubilaciones o al forzar al Congreso a crear un mecanismo automático para la actualización de los beneficios previsionales, el gobierno se vio forzado a asignar partidas presupuestarias suficientes para cumplir los nuevos estándares fijados por las sentencias del tribunal.

El impacto de estas sentencias de la Corte Suprema fue novedoso ya que generó cambios concretos en la política pública previsional del Estado. Las modificaciones no fueron menores, ya que, por ejemplo, se simplificó el proceso judicial para reclamar actualizaciones mediante la eliminación del sistema de apelaciones

Página 12, 7/9/2006. 'La Corte y las cárceles'.

Clarín, 6/8/2006. 'La Justicia se involucra cada vez más en políticas sociales'.

Clarin, 6/9/2006. 'Dicen que en cinco años ya se verán mejoras en el Riachuelo'. 
ordinarias puesto en marcha por el Congreso en 1995 y se reconoció la vigencia de los regímenes jubilatorios especiales. Sin embargo, uno de los efectos más destacados fue lograr que el Poder Legislativo sancionara un nuevo mecanismo para implementar de manera efectiva la garantía de la movilidad automática. Esto último es especialmente novedoso en la vida institucional argentina.

El caso analizado sugiere que la Corte Suprema puede convertirse en un actor relevante en el proceso de formulación de políticas públicas. En este caso, el Tribunal no sólo tuvo un rol protagónico en la redefinición de alguno de los aspectos centrales de la política previsional sino que lo hizo procurando objetivos distintos a los del Poder Ejecutivo. En este sentido, la Corte logró imponer reformas que claramente contrariaban las preferencias del gobierno en materia previsional. Esto representa un cambio notorio, por ejemplo, con relación al comportamiento del tribunal -en su anterior composición- durante la década de 1990, cuando apoyó de manera casi sistemática las necesidades y expectativas del entonces presidente Carlos Menem, o de etapas anteriores en las cuales no tuvo una incidencia semejante en materia de políticas públicas (Verbitsky 1993; Herrero 2007).

\section{Bibliografía}

AlCÁNTARA SÁEZ, MANUEl. 1995. Gobernabilidad, crísis y cambio: elementos para el estudio de la gobernabilidad de los sistemas políticos en épocas de crisis y cambio. México: Fondo de Cultura Económica.

Bertranou, Fabio; Rofman, RAfael; GrushKa, CARlos. 2003. "From reform to crisis: Argentina's pension system”. International Social Security Review 56: 103-114.

DAHL, RoBerT. 1957. Decision-Making in a Democracy: The Supreme Court as a National Policy Maker. Journal of Public Law 6: 279-295.

DiAMOND, LARRY; LINZ, JUAN; LIPSET, SEYMOUR. 1990. Democracy in developing countries. Boulder, Colorado: L. Rienner.

Domingo, Pilar. 2005. Judicialisation of Politics: The Changing Political Role of the Judiciary in Mexico. En Rachel Sieder et al. (eds.), The Judicialisation of Politics in Latin America. New York: Palgrave McMillan.

FEELEY, MALCOLM; RUBIN, EDWARD L. 1998. Judicial policy making and the modern state: how the courts reformed America's prisons. Cambridge criminology series. Cambridge, U.K.: Cambridge University Press.

FEREJOHN, JOHN, 2002. "Judicialización de la política, politización de la ley". Revista Mexicana de Ciencias Politicas y Sociales 184: 13-49. Disponible en http://redalyc.uaemex. $\mathrm{mx} /$ redalyc/src/inicio/ArtPdfRed.jsp?iCve=42118402.

FINKEL, JODI S. 2004. "Judicial Reform in Argentina in the 1990s: How Electoral Incentives Shape Institutional Change”. Latin American Research Review 39 (3): 56-80.

FINKEL, JODI S. 2008. Judicial reform as political insurance: Argentina, Peru, and Mexico in the 1990s. Notre Dame, Indiana: University of Notre Dame Press.

Ginsburg, TOM. 2003. Judicial review in new democracies constitutional courts in Asian cases. Cambridge, UK: Cambridge University Press.

Gloppen, Siri; Gargarella, RoberTo; SKaAR, Elin. 2004. Democratization and the judiciary: the accountability function of courts in new democracies. London: Frank Cass. 
La incidencia de la Corte Suprema de Justicia en la formulación de políticas públicas...

Guarnieri, Carlo; Pederzoli, Patrizia; Thomas, C. A. 2002. The power of judges: a comparative study of courts and democracy. Oxford socio-legal studies. Oxford: Oxford University Press.

Helmke, Gretchen 2003. Checks and Balances by Other Means: Strategic Defection and the 'Re-Reelection' Controversy in Argentina. Comparative Politics 35 (2): 213228.

Helmke, Gretchen. 2005. Courts under constraints: judges, generals, and presidents in Argentina. Cambridge studies in comparative politics. Cambridge, UK: Cambridge University Press.

Herrero, Álvaro. 2007. Court-Executive Relations in Unstable Democracies: Strategic Judicial Behaviour in Post-Authoritarian Argentina (1983-2005). Thesis (D.Phil), University of Oxford, Dept. of Politics and International Relations.

Huntington, SAMUEL P. 1996. The clash of civilizations and the remaking of world order. New York: Simon \& Schuster.

IARYCZOWER, MATÍAS; SPILLER, PABLO; TOMMASI, MARIANO. 2000. Un enfoque estratégico para entender el comportamiento de la Corte Suprema de Justicia de la Nación. Buenos Aires: Centro de Estudios para el Desarrollo Institucional.

IARYCZOWER, MATías; SPIller, PAblo; TOMmasi, Mariano. 2006. "Judicial Lobbying: The Politics of Labor Law Constitutional Interpretation". American Political Science Review. 100 (1): 85-97.

JACKSON, DONALD WILSON; TATE, C. NEAL. 1992. Comparative judicial review and public policy. Contributions in political science, $\mathrm{N}^{\mathrm{O}} 306$. Westport, Connecticut: Greenwood Press.

KAPISZEWSKI, DiAnA. 2005. "The Supreme Court and Constitutional Politics in PostMenem Argentina”. American Political Science Association - Conference Proceeding, Washington DC, September 1-4.

Koski, WilLiam S. 2004. "The Politics of Judicial Decision-Making in Educational Policy Reform Litigation”. The Hastings Law Journal 55 (5): 1077.

LARKINS, CHRISTOPHER. 1998a. The legacies of hyper-presidentialism: executive-judicial relations, constitutional cultures, and the future of democratic governance in Argentina and Peru. Thesis (Ph. D.), University of Southern California.

LARKINS, CHRISTOPHER. 1998b. "The Judiciary and Delegative Democracy in Argentina". Comparative Politics 30 (4): 423-442.

LinZ, JuAn; STEPAN, AlFReD. 1996. Problems of democratic transition and consolidation: southern Europe, South America, and post-communist Europe. Baltimore: Johns Hopkins University Press.

MAlamud Goti, JAime E. 1996. Game without end state terror and the politics of justice. Norman: University of Oklahoma Press.

Nino, CARlos SAntiago. 1997. Juicio al mal absoluto. Buenos Aires, Argentina: Emecé.

O'DONNEll, GuILlERMO; SCHMITTER, PHILIPPE. 1986. Transitions from authoritarian rule. Tentative conclusions about uncertain democracies. Baltimore: Johns Hopkins University Press.

O’Donnell, Guillermo; Schmitter, PhilipPe; WhiteheAd, LAurence. 1986. Transitions from authoritarian rule: prospects for democracy. Baltimore: Johns Hopkins University Press.

O'Donnell, Guillermo; Whitehead, Laurence; Schmitter, Philippe. 1988. Transiciones desde un gobierno autoritario. 2, América Latina. Estado y sociedad. Buenos Aires: Paidós.

Peters, B. GuY. 1982. American public policy: process and performance. New York: F. Watts. 
Przeworski, Adam; Stokes, Susan Carol; Manin, Bernard. 1999. Democracy, accountability, and representation. Cambridge studies in the theory of democracy. Cambridge, U.K.: Cambridge University Press.

ROFMAN, RAFAEL. 2000. The pension system in Argentina six years after the reform. Washington, DC: World Bank.

Rofman, Rafael. 2002. "The Pension System and the Crisis in Argentina: Learning the Lessons". Disponible en http://www.brandeis.edu/ibs/rosenberg_papers/rofman_paper.pdf (Visitado el 10/07/2006)

ROSENBERG, GERALD N. 1991. The hollow hope: can courts bring about social change? Chicago: University of Chicago.

Shaw, StePhen; Pederson, William; Williams, Frank. 2004. Franklin D. Roosevelt and the transformation of the Supreme Court. The M.E. Sharpe library of Franklin D. Roosevelt studies, v. 3. Armonk, N.Y.: M.E. Sharpe.

Shapiro, MARTIN M. 1968. The Supreme Court and administrative agencies. New York: Free Press.

SHAPIRO, MARTIN M. 1981. Courts, a comparative and political analysis. Chicago: University of Chicago Press.

SChedler, Andreas; Diamond, LARry; PlatTner, Marc F. 1999. The self-restraining state: power and accountability in new democracies. Boulder, Colo: Lynne Rienner Publishers.

Sieder, Rachel; Schjolden, Line; Angell, Alan. 2005. The judicialization of politics in Latin America. Studies of the Americas. New York: Palgrave Macmillan.

STATON, JEFFREY KAPLAN. 2002. Judicial activism and public authority compliance: the role of public support in the Mexican separation-of-powers system. Thesis (Ph. D.), Washington University, Dept. of Political Science.

STOTZKY, IRWIN P. 1993. Transition to democracy in Latin America: the role of the judiciary. Boulder: Westview Press.

Teitel, Ruti G. 2002. Transitional justice. Oxford: Oxford Univ. Press.

Tsebelis, GEORGE. 2002. Veto players: how political institutions work. Princeton, N.J.: Princeton University Press.

VANBERG, G. 2001. "Legislative-Judicial Relations: A Game-Theoretic Approach to Constitutional Review". American Journal of Political Science 45: 346-361.

VERBITSKY, HORACIO. 1993. Hacer la corte: la construcción de un poder absoluto sin justicia ni control. Buenos Aires: Planeta. 
La incidencia de la Corte Suprema de Justicia en la formulación de políticas públicas...

\section{Anexo}

Resumen de los casos analizados

\begin{tabular}{|c|c|c|c|}
\hline AÑo & EVENTO & $\begin{array}{l}\text { PREFERENCIAS DEL } \\
\text { PODER EJECUTIVO }\end{array}$ & $\begin{array}{c}\text { RESPUESTA DE LA CORTE } \\
\text { SUPREMA }\end{array}$ \\
\hline 2005 & $\begin{array}{l}\text { Eliminación de la apelación or- } \\
\text { dinaria en material previsional } \\
\text { ante la Corte Suprema creada } \\
\text { por Ley } 24.463 \text { ('Itzcovich') }\end{array}$ & $\begin{array}{l}\text {-Preocupación por la } \\
\text { carga fiscal derivada de la } \\
\text { aceleración de los juicios. }\end{array}$ & $\begin{array}{l}\text {-Declaró inconstitucional } \\
\text { la apelación ordinaria de la } \\
\text { Ley } 24.463 .\end{array}$ \\
\hline 2005 & $\begin{array}{l}\text { Aplicación de un nuevo ajuste } \\
\text { de movilidad para el periodo } \\
\text { 1991-1995 -o el rechazo a } \\
\text { 'Chocobar'. } \\
\text { ('Sanchez') }\end{array}$ & $\begin{array}{l}\text {-El Poder Ejecutivo había } \\
\text { otorgado sucesivos au- } \\
\text { mentos. } \\
\text {-Preocupación por el im- } \\
\text { pacto fiscal de un posible } \\
\text { fallo que revirtiera los } \\
\text { efectos de 'Chocobar'. }\end{array}$ & $\begin{array}{l}\text {-Revirtió el precedente de } \\
\text { 'Chocobar'. } \\
\text {-Reconoció un ajuste del } \\
38 \% \text {, en lugar del de 13\% } \\
\text { otorgado por 'Chocobar'. } \\
\text {-Determinó la vigencia de } \\
\text { los ajustes por movilidad } \\
\text { entre } 1991 \text { y } 1995 .\end{array}$ \\
\hline 2005 & $\begin{array}{l}\text { Vigencia de los regímenes } \\
\text { especiales de jubilación. } \\
\text { ('Gemelli') }\end{array}$ & $\begin{array}{l}\text {-El Poder Ejecutivo se ne- } \\
\text { gaba a reconocer y poner } \\
\text { en vigor el estándar del } \\
82 \% \text { móvil, tanto por vía } \\
\text { legislativa o judicial. } \\
\text {-Negaba la vigencia de los } \\
\text { regímenes especiales de } \\
\text { jubilación. } \\
\text {-Preocupación por el } \\
\text { impacto fiscal. }\end{array}$ & $\begin{array}{l}\text {-Reconoció la vigencia de } \\
\text { los regímenes especiales, } \\
\text { primero de los docentes y } \\
\text { luego de otros sectores. } \\
\text {-Reafirmó la validez de los } \\
\text { ajustes por movilidad para } \\
\text { los regímenes especiales. }\end{array}$ \\
\hline $\begin{array}{l}2006 \\
2007\end{array}$ & $\begin{array}{l}\text { Aplicación de ajuste por } \\
\text { movilidad para todas las jubi- } \\
\text { laciones. } \\
\text { (Badaro I y II) } \\
\text { Comentario: Badaro I fue en } \\
2006 \text { y el II en } 2007\end{array}$ & $\begin{array}{l}\text {-Rechazaba la posibilidad } \\
\text { de poner en vigencia } \\
\text { mecanismos para el ajuste } \\
\text { automático de las jubila- } \\
\text { ciones. } \\
\text {-Profunda preocupación } \\
\text { por el impacto fiscal. } \\
\text {-Preservar el statu quo y } \\
\text { que el Poder Ejecutivo } \\
\text { otorgue aumentos a su } \\
\text { sola discreción. }\end{array}$ & $\begin{array}{l}\text {-Reconoció la ilegalidad de } \\
\text { la ausencia de movilidad } \\
\text { automática. } \\
\text {-Exhortó al Congreso a } \\
\text { que sancione un nuevo } \\
\text { marco para ajustar auto- } \\
\text { máticamente las jubila- } \\
\text { ciones. } \\
\text {-Frente a la inacción ini- } \\
\text { cial del Congreso, fijó una } \\
\text { movilidad del 88,5\%. } \\
\text {-Finalmente logró que el } \\
\text { Congreso sancione una ley } \\
\text { de movilidad automática. }\end{array}$ \\
\hline
\end{tabular}

Fuente: Elaboración propia 